

\title{
Pretreatment of Lignocellulosic Biomass Using Vortex-Based Devices for Cavitation: Influence on Biomethane Potential
}

Nagarajan, S., \& Ranade, V. V. (2019). Pretreatment of Lignocellulosic Biomass Using Vortex-Based Devices for Cavitation: Influence on Biomethane Potential. Industrial and Engineering Chemistry Research. https://doi.org/10.1021/acs.iecr.9b00859

\section{Published in:}

Industrial and Engineering Chemistry Research

\section{Document Version:}

Peer reviewed version

Queen's University Belfast - Research Portal:

Link to publication record in Queen's University Belfast Research Portal

\section{Publisher rights}

(C) 2019 American Chemical Society.

This work is made available online in accordance with the publisher's policies. Please refer to any applicable terms of use of the publisher.

\section{General rights}

Copyright for the publications made accessible via the Queen's University Belfast Research Portal is retained by the author(s) and / or other copyright owners and it is a condition of accessing these publications that users recognise and abide by the legal requirements associated with these rights.

Take down policy

The Research Portal is Queen's institutional repository that provides access to Queen's research output. Every effort has been made to ensure that content in the Research Portal does not infringe any person's rights, or applicable UK laws. If you discover content in the Research Portal that you believe breaches copyright or violates any law, please contact openaccess@qub.ac.uk. 
Pre-treatment of Lignocellulosic Biomass using Vortex based Devices for Cavitation: Influence on Biomethane Potential

Sanjay Nagarajan and Vivek V. Ranade* Multiphase flows, reactors and intensification group School of Chemistry and Chemical Engineering Queen's University Belfast, Belfast - BT9 5AG, United Kingdom

*corresponding author - V.Ranade@qub.ac.uk

\begin{abstract}
Lignocellulosic biomass (LCB) is an abundant renewable resource to produce fuels and chemicals. Valorisation of $L C B$, is however a challenge due to its recalcitrant nature posed by the strongly interlinked cellulose-lignin-hemicellulose structures. A range of physico-chemical and biological LCB pre-treatment methods have been reported in literature for enhancing its bio-utilisation. In this work, we used hydrodynamic cavitation (HC) based on vortex devices as a chemical free, environment friendly LCB pre-treatment method to enhance biomethane production. A bench scale pre-treatment set-up using a vortex based cavitation device was established for the pre-treatment of two common LCB's - grass silage (GS) and sugar cane bagasse (SCB). Dried and powdered feedstocks were used in all the experiments. $\mathrm{HC}$ was carried out by operating the cavitation device at a flow rate of $\sim 1.5 \mathrm{~m}^{3} / \mathrm{hr}$. The feedstocks before and after pre-treatment were characterised for morphological and compositional differences using a range of analytical techniques. Liquid phase products produced upon cavitation were also analysed using a HPLC-RI. Biomethane potential (BMP) was measured for GS and SCB with and without pre-treatment, and a first order model was used to describe the kinetics. Up to $40 \%$ enhancement was observed in BMP after cavitation pre-treatment using vortex based devices. A brief discussion on preliminary cost considerations based on the experimentally observed enhancement in BMP is included. The results indicate significant promise of harnessing hydrodynamic cavitation based pre-treatment using vortex based devices for enhancing biomethane production from LCB.
\end{abstract}

Keywords: Anaerobic digestion, biomass, hydrodynamic cavitation, pre-treatment, enhanced biogas. 


\section{Introduction}

Significant value addition can be realised by transforming waste lignocellulosic biomass (LCB) into biofuels. LCB, while abundant and cheap, cannot be valorised easily because of its complex interlinked structure of cellulose, hemicellulose and lignin ${ }^{1}$. Several ways of valorising biomass in the form of biofuels or value added platform chemicals have been reported in literature ${ }^{2-15}$ which may be broadly grouped as (1) gasification/pyrolysis, (2) catalytic reactions and (3) biochemical conversions. Each of the valorisation avenues have many variants within these broad three groups and have specific advantages and disadvantages associated with them. In this work, we focus on biochemical valorisation of $L C B$ using anaerobic digestion (AD). There is an increasing interest in harnessing AD for valorising waste biomass as it is the only closed system that recovers energy, while retaining fertilizer and water content with minimal emissions. Biogas production via $A D$ has been reported earlier using wastes in the form of wastewater and sewage sludge, municipal solid waste, LCB's such as agricultural and forest residues ${ }^{16,17}$. Moreover, the capex and opex of AD plants have shown to be relatively lower than other renewable energy technologies ${ }^{18}$. Therefore, policies are being implemented to boost the installed capacity of AD plants for waste minimisation and biogas production. For example, India's Ministry of Petroleum \& Natural Gas has launched the 'Sustainable Alternative Towards Affordable Transportation' (SATAT) initiative recently to expand the biogas production capacity ${ }^{19}$.

$A D$ processes are rather slow ${ }^{20}$ and hence there is a need for improving its overall productivity and economics. Overall productivity of $A D$ is influenced by numerous factors such as temperature, $\mathrm{pH}$, feedstock recalcitrance, lignin and its derivatives, heavy metals, ammonia and sulphide ${ }^{21,22}$. Amongst these, the key productivity controlling factor is the recalcitrance of the LCB feedstock itself. This limiting factor can be overcome by pre-treating the biomass to enhance its bio-utilisation and digestibility, which forms the basis of this study. It may also be possible to enhance overall economics by deliberately operating $A D$ at lower conversion of $L C B$ and using the digestate containing significant organic matter for further conversion to value added products ${ }^{23,24}$. A conceptual multi-product biorefinery based on $A D$ with cavitation as the pre-treatment step is shown in Figure 1. Cavitation pretreatment of $L C B$ for improving productivity of $A D$ will serve as a first step in realising the bio-refinery shown in Figure 1.

Any successful LCB pre-treatment method should address majority of these following criteria ${ }^{1,25}$,

- Increase available surface area, reduce particle size, decrease structural rigidity and reduce viscosity of biomass slurry (improve flowability of slurry)

- Open the LCB matrix and make cellulose and hemicellulose accessible;

- Enhance sugar formation/hydrolysis without forming inhibitors 
- Scalable and cost-effective



Figure 1: AD based bio-refinery utilising $\mathrm{HC}$ pre-treatment

Existing pre-treatment methods can be broadly classified under four types: physical, chemical, biological and physico-chemical (summarized in Figure S1). Although physical methods offer advantages of producing LCB with smaller particle size, they are energy intensive (energy required may range between $0.4-0.8 \mathrm{kWh} / \mathrm{kg}$ total solids ${ }^{26}$ for drying and $0.03-0.81 \mathrm{kWh} / \mathrm{kg}$ total solids for milling ${ }^{27,28}$ ). Moreover, these physical methods do not effectively open up lignocellulosic matrix on a molecular scale. Established chemical methods such as alkali or acid hydrolysis generate inhibitors and are toxic or corrosive that almost always requires $\mathrm{pH}$ adjustment to make sure that it is suitable for microbial growth and metabolism for fermentation or digestion ${ }^{29}$. Microbial and enzymatic methods require low energy, are highly specific for hydrolysing polysaccharides and do not generate inhibitors. However, they are expensive, require large quantities of enzymes to compensate for the loss of enzymes due to wash out as well as suffer from slow rates. Physico - chemical pre-treatment methods on the other hand have a potential to overcome some of these disadvantages. For instance, a physico-chemical method such as steam explosion requires $70 \%$ lower energy than physical methods and does not use toxic chemicals ${ }^{29}$. However due to the loss of a fraction of hemicellulose and possible inhibitory compound formation during steam explosion, hot water treatment has been used as an alternative ${ }^{30}$. Although preferred over steam explosion, its major disadvantage is the energy demand for downstream processing due to the large volumes of water involved. Other physico-chemical methods such as ammonia explosion or acid hydrolysis combined with steam explosion have also been proposed. However, these incur significant costs for recovery of the chemicals and neutralisation required prior to biofuel production. 
Cavitation has been claimed as an effective pre-treatment offering several advantages over other pretreatment methods ${ }^{31}$ and have been increasingly used for LCB pre-treatment ${ }^{32-39}$. Cavitation is the phenomenon of formation, growth and rapid collapse of vaporous microbubbles, known as cavities. Collapse of cavities generate localised hotspots with very high pressures and temperatures as well as intense localised shear ${ }^{40}$. The localised high pressure and temperatures lead to the formation of reactive oxygen species (ROS), predominantly, highly oxidant $\mathrm{OH}$ radicals. The shear and ROS formed are responsible for physico-chemically pre-treating the LCB. Cavitation can be realised ultrasonically (acoustic cavitation, AC) or hydrodynamically (hydrodynamic cavitation, $\mathrm{HC}$ ). Due to the advantages offered by HC systems compared to AC systems such as energy input and scalability, HC is almost always preferred for large scale processes. For instance, Langone et al. reported that LCB pretreatment using $\mathrm{HC}$ technologies required $0.44-0.66 \mathrm{kWh} / \mathrm{kg}$ total solids whereas the energy requirement for $\mathrm{AC}$ systems was significantly higher ${ }^{41}$.

$\mathrm{AC}$ and $\mathrm{HC}$ have been studied in the past (with or without combining it with chemical pre-treatment) for the pre-treatment of a range of LCBs for biofuel production. A summary of some of these studies is shown in Table S1. Use of in-line HC devices for pre-treatment without using any external chemicals appears to be a promising option. Some efforts are being made to offer commercial pre-treatment solutions based on this. See for example, offerings of CAVIMAX, BIOBANG, ARISDYNE, and VIVIRA ${ }^{42-}$ 45. Despite these commercialisation efforts, a systematic evaluation of HC based pre-treatment of different LCB is still lacking. In this work, we present the influence of $\mathrm{HC}$ based pre-treatment on BMP of two abundant substrates that has the potential to contribute towards the bio-economy: the first one is relevant to Northern Ireland, UK (and many parts of Europe): grass silage (GS). As of 2016, Northern Ireland produced around 9 million tonnes of grass silage annually ${ }^{46}$. The second one is relevant to India (and many other tropical countries): sugar cane bagasse (SCB). India generates nearly 80 million tonnes of SCB every year ${ }^{47}$.

Though GS is often mentioned in literature as an excellent co-digestion feedstock for biogas production, no studies on cavitation pre-treatment of GS were reported. The closest we could find were using animal slurry and other kinds of silage as feedstock or just grass as feedstock. For instance, Garuti et al. ${ }^{32}$ reported the use of a rotor-stator assembly as the $\mathrm{HC}$ device for pre-treating a feed slurry consisting of animal manure, beet residue, maize and triticale silage. They performed HC tests at specific energy inputs of 470,740 and $954 \mathrm{~kJ} / \mathrm{kg}$ total solids $(0.126,0.205$ and $0.265 \mathrm{kWh} / \mathrm{kg}$ total solids respectively) and stated that the improvement in biogas production of $14 \%$ was observed until the specific energy input of $740 \mathrm{~kJ} / \mathrm{kg}$ total solids. When the specific energy input further increased, the enhanced output fell by $2.9 \%$. This was attributed to the release of inhibitors such as phenolics, 
HMF and others from the feedstock into solution due to cavitation. Contrastingly, in the work reported by Zieliński et al. ${ }^{33}$ where $\mathrm{AC}$ and $\mathrm{HC}$ treatment of a mix of cattle manure and wheat straw were used as feedstock, no drop in biogas production with increase in cavitation time was reported. This may therefore partially be due to the nature and composition of the co-digestion feedstock used along with the animal slurry.

For SCB, combination of $\mathrm{HC}$ with alkali pre-treatment have been reported ${ }^{34-36}$. A hybrid alkali-HC pretreatment was reported to be preferential for the removal of lignin as well as to enhance the hydrolytic sugar yield. In general, from a thorough review, it was seen that $\mathrm{HC}$ was energetically favourable when compared to AC. The reported studies of hydrodynamic cavitation based pre-treatment have used HC devices such as the orifice, venturi or a rotor-stator assembly. In all these devices, cavitation occurs near solid surfaces and causes erosion, and therefore leads to a shorter equipment life time. The presence of small constrictions or gaps used in these devices are prone to clogging and related operational issues ${ }^{48}$.

Ranade et al. ${ }^{49}$ recently disclosed a patented device known as the vortex based devices for cavitation which have the capability to overcome these limitations offered by the conventional HC devices. This device claims to offer a longer life time than conventional devices as cavities form and collapse in the core of the flowing liquid (away from solid walls). The device does not have small constrictions and hence it is not susceptible to clogging. The vortex based cavitation has been shown to perform 3 to 8 times better than conventional devices such as orifice on the basis of cavitational yield for wastewater treatment ${ }^{50}$. Considering these advantages, the use of vortex based cavitation devices for the pretreatment of LCB was investigated in this work.

In the present study, we have investigated vortex based cavitation pre-treatment of two most commonly available, inexpensive LCB, namely SCB and GS with the aim of enhancing biogas production. Biogas production was determined using biochemical methanation potential (BMP) tests. Detailed characterisation of the solids and liquids upon HC treatment was also performed to determine the differences (if any) between the untreated and cavitated feedstock. A brief discussion on costs and benefits of pre-treatment is included at the end. It is expected that the results presented here will stimulate further work on harnessing $H C$ for pre-treating $L C B$ and developing an $A D$ based biorefinery for deriving better value out of abundantly available feedstocks such as SCB and GS.

\section{Methodology}

\subsection{Substrate and inoculum collection and preparation}

GS was obtained from a UK based AD plant operated by Agri-Food and Biosciences Institute (AFBI). SCB was obtained from Dhampur sugar mills, India. Obtained feedstock were dried in a Carbolite Gero 
oven at $105^{\circ} \mathrm{C}$ for $24 \mathrm{hrs}$. A POLYMIX PX-MFC-90D grinder mill with a $2 \mathrm{~mm}$ sieve fitting was used to mill the biomass. Inoculum used for biochemical methanation potential (BMP) tests were obtained from AFBI.

\subsection{Pre-treatment methodology}

A HC rig with flow circuit (Figure 2) similar to the configuration reported in literature ${ }^{34-38,51-55}$ for $\mathrm{HC}$ pre-treatment of biomass and wastewater treatment was designed for this work. It was ensured that with the required operating conditions, cavitation only occurred in the vortex based device but not in the valves or pump. Further details on the material of construction of the rig components and the flow configuration are given in the supplementary information. The $\mathrm{HC}$ device used in this work with a nominal capacity of $1.2 \mathrm{~m}^{3} / \mathrm{hr}$ was manufactured in stainless steel and was procured from Vivira Process Technologies, India (www.vivira.in). The details of the device can be found in Ranade et al. ${ }^{49}$. The photograph of the constructed rig is shown in Figure S2. In typical HC experiments, tap water (15 L working volume) was first allowed to recirculate through the system from the holding tank. Then the bypass line was fully closed to achieve full flow through the main line (through the vortex based HC device) at a flow rate of $1.54 \mathrm{~m}^{3} / \mathrm{hr}$ and at an inlet pressure of $3.9 \mathrm{barg}$. The desired quantity of GS or SCB was then slowly added to the holding tank to achieve a feedstock concentration of $10 \mathrm{~g} / \mathrm{L}$. $1 \mathrm{~L}$ sample was then collected after 9, 36 and 117 passes via the sampling line. These samples were then characterised and used for BMP tests (as discussed in Section 2.4).



Figure 2: Schematic of experimental rig for LCB pre-treatment. ('A' - holding tank, 'B' - Feed line to the pump, ' $C$ ' - Progressive cavity pump, ' $D$ ' - Bypass line back to the holding tank, ' $E$ ' - Inlet line for the vortex based cavitation device, ' $F$ ' -Pressure gauge, ' $G$ ' -Vortex based cavitation device, ' $\mathrm{H}$ ' Device outlet line back to the holding tank and ' $I$ ' - Sampling line) 


\subsection{Untreated and cavitated substrate characterisation}

A Brunel SP400 microscope equipped with a Canon EOS 2000D camera was used to capture the images of the solids before and after pre-treatment to visually monitor the morphological changes occurring to LCB upon cavitation. Subsequently for proximate analysis, $1 \mathrm{~g}$ of untreated feedstock was weighed, in triplicates, into the crucibles. The crucibles were then placed in the oven at $105^{\circ} \mathrm{C}$ for $24 \mathrm{hrs}$. The dried samples in crucibles were then left to cool to ambient temperature and then weighed again to determine the moisture lost and dry weight (total solids, TS) remaining. The samples were then placed in a SNOL $13 / 1100$ LHM01 muffle furnace at $550{ }^{\circ} \mathrm{C}$ for $2 \mathrm{hrs}$. Upon cooling the crucibles to ambient temperature, weight of the ash left behind was recorded and the volatile solids (VS) lost was calculated ${ }^{56}$.

Fourier-Transform-Infrared Spectroscopy (FTIR) spectra of untreated and cavitated feedstock (dried and powdered) were taken with an Agilent Technologies Cary 630 FTIR fitted with a diamond attenuated total reflectance attachment. An average of 16 scans was taken per sample, at room temperature and in the wavenumber range of $4000-650 \mathrm{~cm}^{-1}$. These profiles were was used to identify the presence of various bonds and functional groups that are specific to GS and SCB. The characteristic absorption/transmission of infrared by each of the functional groups were identified and compared against previously reported data and also used to describe the effect of pre-treatment.

Thermogravimetry analysis (TGA) was performed using a Mettler Toledo TGA/DSC 1 STARe system on the dried and powdered, untreated and cavitated feedstock. The thermal degradation profiles were recorded over a range of $50-1000^{\circ} \mathrm{C}$ and at a $20^{\circ} \mathrm{C} / \mathrm{min}$ heating rate under $\mathrm{N}_{2}$ atmosphere. Derivative thermogravimetric (DTG) data was then used to determine the rate of weight loss. Each component of the LCB has a characteristic thermal degradation profile and this was used to qualitatively (and in some instances quantitatively) identify the changes to each of the fractions present in LCB upon cavitation.

XRD was used to determine the changes to crystallinity of the LCB before and after cavitation. The profiles of untreated and cavitated LCB were obtained using a PANalytical PW3719 powder diffractometer. A spinner cell PW3064 was used to capture the profiles. The wavelength of the X-ray radiation was $1.54 \AA$. The generator voltage and current were set at $40 \mathrm{kV}$ and $40 \mathrm{~mA}$. The diffraction pattern was recorded between the $2 \Theta$ ( 2 Theta) range of $5-45^{\circ}$ with a scan step size of $0.0167 \mathrm{~s}^{-1}$. The diffraction patterns were recorded using an X'Pert data collector software. Crystallinity index (Crl) was also calculated ${ }^{57}$.

The liquid phase analysis was performed using a high-performance liquid chromatography system equipped with a refractive index detector (HPLC-RI). An Agilent 1260 infinity HPLC hosting a Rezex 
ROA-Organic Acid $\mathrm{H}+$ column $(300 \times 7.8 \mathrm{~mm})$ was used for analysis. $5 \mathrm{mM} \mathrm{H}_{2} \mathrm{SO}_{4}$ was used as the mobile phase. A flow rate of the mobile phase was set at $0.5 \mathrm{ml} / \mathrm{min}$ and a sample volume of $10 \mu \mathrm{l}$ was withdrawn for product analysis. The unknown samples were measured against predetermined HPLC profiles of respective commercial products. For unknown peaks, the peak areas were determined and the possible compounds eluting at those retention times were hypothesised based on the type of feedstock used, the HPLC column used and the order of elution.

\subsection{Biochemical methanation potential}

\subsubsection{BMP experimental set up}

One litre samples of pre-treated slurry were used for BMP tests. Solids and liquids from the collected samples were separated using a kitchen sieve with a mesh size of $\sim 1 \mathrm{~mm}$. Separated solids were then dried at $105^{\circ} \mathrm{C}$ for $24 \mathrm{hrs}$ in the oven and stored at room temperature whereas the liquids were stored in a fridge at $4{ }^{\circ} \mathrm{C}$ before characterisation. Untreated LCB was soaked in water at a concentration of $10 \mathrm{~g} / \mathrm{L}$ and processed in the same manner as the pre-treated slurry. Two sets of BMP tests were performed. In the first set, only the separated solids from the slurry were subjected to BMP tests, the dry solids were mixed with the inoculum and fresh tap water of desired volume to make up the working digester volume. The second set of BMP tests were performed with the slurry samples. The corresponding amounts of dry solids and separated liquids were mixed to prepare the slurry and then mixed with the inoculum. The solids obtained from the single HC runs were subjected to BMP tests in duplicates.

BMP tests of the treated and untreated samples were performed using a gas endeavour system or an automatic methane potential test system (AMPTS) II (Bioprocess control, Sweden). The method reported by Stromberg et al, $2014{ }^{58}$ was modified and used in this work. Briefly, BMP reactors with a total volume of $500 \mathrm{ml}$ and a working volume of $400 \mathrm{ml}$ ( $200 \mathrm{ml}$ in some cases) fitted with an overhead stirrer were used for anaerobic digestion. The inoculum was filtered digestate collected from AFBI AD that operated at $41{ }^{\circ} \mathrm{C}$. Hence to replicate similar conditions, instead of the typical $37^{\circ} \mathrm{C}$, the BMP reactors were placed in a water bath at $41{ }^{\circ} \mathrm{C}$. The VS content ratio of inoculum to feedstock was maintained at 2:1 for all cases. The gas generated in the bottles were made to pass through bottles containing $80 \mathrm{ml}$ of $3 \mathrm{M} \mathrm{NaOH}$ and $0.4 \%$ thymolphthalein $\mathrm{pH}$-indicator solution to strip the $\mathrm{CO}_{2}$ and $\mathrm{H}_{2} \mathrm{~S}$ from the generated gas. The stripped gas composed of primarily methane was then passed through respective flow cells to determine the volume of methane produced. The data was logged automatically on to a computer as and when the counter ticked. The BMP tests were performed until a plateau in cumulative biomethane production was observed. 


\subsubsection{Kinetics of BMP - first order model}

The experimentally measured values of BMP were compared with the theoretical BMP calculated based on the elemental composition ${ }^{59}$. Considering the composition of the substrate as $\mathrm{C}_{x} \mathrm{H}_{y} \mathrm{O}_{z}$, the theoretical biomethane potential, $\mathrm{G}_{\text {th }}\left(\mathrm{LCH}_{4} / \mathrm{kg}\right.$ feedstock at STP) may be written as:

$G_{t h}=\frac{\left(\frac{x}{2}+\frac{y}{8}-\frac{z}{4}\right) \times 22.4}{12 x+y+16 z}$

The theoretical estimates of BMP do not consider the non-biogas forming components in LCB such as lignins ${ }^{60}$ or take into account the enzymatic limitations of the microbial consortia and therefore are larger than the experimentally measured BMP.

It is useful to interpret the measured BMP data with appropriate mathematical framework to obtain key LCB digestibility characteristics quantitatively. Most of the models used for interpreting BMP data assume first order kinetics. There are several versions of BMP models (see Strömberg et al. ${ }^{61}$ and Beuvink and Kogut ${ }^{62}$ ), which may be broadly grouped into following two categories:

- $\quad$ Time invariant rate constant of digestion

- $\quad$ Decaying rate constant (with time) of digestion

In each of these categories, there are several variations based on number of rate constants considered in the model. If the digestion rate constant, $k$, is considered to be time invariant and substrate consumption is considered as a first order reaction, the consumption of substrate may be described as:

$\frac{d S}{d t}=-k S \quad$ which gives $\quad S=S_{0} e^{-k t}$

Where $\mathrm{S}$ is the amount of feedstock $(\mathrm{kg})$, $\mathrm{S}_{\mathrm{o}}$ is the initial amount of feedstock $(\mathrm{kg}), \mathrm{k}$ is digestion rate constant (1/day) and ' $t$ ' is time (day). The biomethane generated at time $t$ may be related with the consumption of substrate as:

$G=Y G_{t h}\left(S_{0}-S\right)$

where $\mathrm{Y}$ is an empirical 'yield factor' and $\mathrm{G}_{\text {th }}$ is theoretical biomethane potential (Equation 1).

Using Equations (2) and (3), we may write:

$\frac{d G}{d t}=-k\left(G_{\max }-G\right) \quad$ where $\quad G_{\max }=Y G_{t h} S_{0}$

This gives the following relationship of biomethane generated, $\mathrm{G}$ and time:

$G=G_{\max }\left(1-e^{-k t}\right)$ 
where $\mathrm{G}$ is the amount of biomethane generated ( $\mathrm{L} \mathrm{CH}_{4} / \mathrm{kg}$ feedstock) and $\mathrm{G}_{\max }$ is the biomethane potential or the maximum biomethane that could be generated ( $\mathrm{LCH}_{4} / \mathrm{kg}$ feedstock). Equation (5) may be used to fit the experimentally measured biomethane generation with time. It has two parameters: digestion rate constant, $\mathrm{k}(1 /$ day) and yield factor, $\mathrm{Y}$ (dimensionless). However, owing to the uncertainties in estimating biomass composition and theoretical BMP $\left(G_{t h}\right)$, it may be convenient to consider $\mathrm{G}_{\max }$ as a second parameter of Equation (5). It was observed in some experiments that the initial digestion rate of substrate is very low. The digestion rate was found to pick up after certain delay time. Cases with delay time may be interpreted by assuming two phases of digestion with two different rate constants. The first phase may be assumed to prevail from the beginning till time $t_{0}$. The maximum gas generation potential through this phase may be denoted as $G_{0}$. The second phase will kick in at $t_{0}$ with rate much higher than the first phase. The overall gas generation may then be described as:

$\frac{d G}{d t}=-k_{1}\left(G_{\max 1}-G\right)$ for $t \leq t_{0}$

$G=G_{\max 1}\left(1-e^{-k_{1} t}\right)=G_{\max 1} k_{1} t$ for small value of $\left(k_{1} t\right)$

Considering the linear behavior, number of parameters may be reduced as:

$G=G_{\max 1}\left(k_{1} t_{0}\right)\left(\frac{t}{t_{0}}\right)=G_{0} \frac{t}{t_{0}} \quad$ for phase $1\left(t \leq t_{0}\right)$

where $G_{0}$ is a product of $G_{\max 1}$ and dimensionless digestion rate constant for the phase $1\left(k_{1} t_{0}\right)$.

The second phase may be described in a standard way by considering $t_{0}$ and $G_{0}$ as a starting point as:

$G=G_{0}+\left(G_{\max }-G_{0}\right)\left[1-e^{-k\left(t-t_{0}\right)}\right]$ for $t \geq t_{0}$

Unlike the models discussed so far, it is possible to consider time varying digestion rate constant for some systems. However, our preliminary analysis indicated that the experimentally observed data can be described adequately without considering time varying rate constants. Therefore, all the subsequent analysis was carried out using the Equation (9).

\subsubsection{Statistical analysis}

Further statistical analysis revealed that there is strong correlation between rate constants and maximum gas generation potentials. It was therefore difficult to obtain unique set of parameters as an optimal fit. Several sets of parameters were able to describe the experimental data equally well (in statistical sense). It was therefore decided to reduce the number of model parameters. Out of the four parameters, the parameter $G_{\max }$ was relatively easy to determine from the experimental data. The value of $G_{\max }$ was taken as the maximum measured value of $G$ which was then rounded off to the next integer. The measured experimental data also in many cases indicated the delay time, $t_{0}$, though not 
as clearly as $G_{\max }$. A few numerical experiments accompanied by evaluation of associated error between experimental values and model predictions were used to pre-determine the values of parameter $t_{0}$ for each case. The non-linear regression was then carried out using Graph Pad Prism 8 statistical analysis software ${ }^{63}$ to obtain remaining two parameters, $G_{0}$ and $k$. The software calculates $95 \%$ confidence intervals using the Gaussian distribution of best fit value obtained from the model.

\section{Results and discussion}

\subsection{Substrate characterisation before and after HC}

Figure 3(a) shows the morphological changes observed under a microscope with $200 \mathrm{X}$ magnification, between untreated and HC treated GS samples. It can be seen that with increase in cavitation time, the defined structural boundaries of GS are disturbed, and a disorganised structure is visible. Similarly, a distorted morphology of the SCB samples with increase in cavitation was also clearly visible in Figure 3 (b) at $50 \mathrm{X}$ magnification. Loosened fibres were also seen in both cases. This demonstrates the physical effects caused by cavitation on LCB. A loosened and distorted LCB particle has a higher surface area compared to a well-defined structure and hence could be more easily accessed by the microbial consortia. Similar results have been reported earlier for $\mathrm{HC}$ and $\mathrm{AC}$ treatments on microcrystalline cellulose and SCB (with and without lime treatment) ${ }^{34}$.

TGA of LCB's before and after cavitation were performed under $\mathrm{N}_{2}$ atmosphere and their corresponding DTG profiles are shown in Figure S3 and Figure S4. Four distinct regions of weight loss were observed for GS, namely $<105{ }^{\circ} \mathrm{C}$ (corresponding to moisture), $105-330{ }^{\circ} \mathrm{C}$ corresponding to hemicellulose, $330-400{ }^{\circ} \mathrm{C}$ corresponding to cellulose and $400-550{ }^{\circ} \mathrm{C}$ corresponding to lignin. The residue observed beyond $550{ }^{\circ} \mathrm{C}$ was quantified as ash. In case of SCB, the regions were similar, with the region $<105{ }^{\circ} \mathrm{C}$ corresponding to moisture, $105-335^{\circ} \mathrm{C}$ corresponding to hemicellulose, $335-405$ ${ }^{\circ} \mathrm{C}$ corresponding to cellulose, $405-550{ }^{\circ} \mathrm{C}$ corresponding to lignin and any residue left behind being quantified as ash. The peak temperature where maximum weight loss was observed for GS and SCB corresponded to its cellulose fractions and the temperatures were recorded to be $365{ }^{\circ} \mathrm{C}$ and $373{ }^{\circ} \mathrm{C}$ respectively and the shoulders corresponding to hemicellulose had a peak weight loss at $300-315{ }^{\circ} \mathrm{C}$ and $315-320{ }^{\circ} \mathrm{C}$ respectively. Similar trends have been observed during TGA of GS and SCB under $\mathrm{N}_{2}$ atmospheres in literature ${ }^{64,65}$.

The compositional information of the LCB were determined from literature and they correspond to a cellulose, hemicellulose and lignin content of $20-34 \%, 13-29 \%$ and $8-32 \%$ for GS ${ }^{66-69}$ and $37-45 \%$, $24-31 \%$ and $11-24 \%$ for $\mathrm{SCB}{ }^{70-73}$. These reported values were determined using traditional wet chemistry methods. The TGA data in principle may be used to estimate approximate composition of biomass since the different fractions of biomass have different maximum rates of decomposition and 


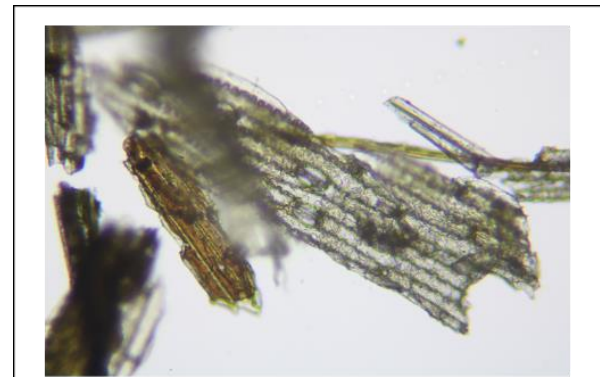

Untreated GS

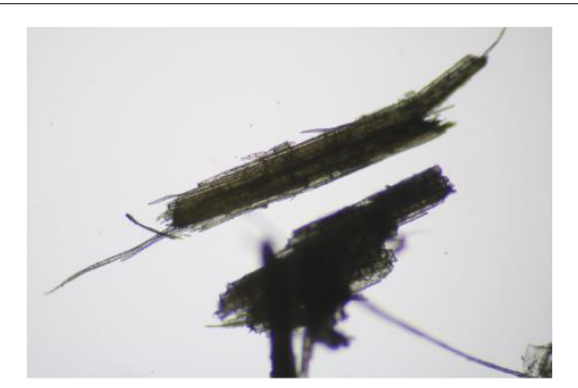

Untreated SCB



GS after $0^{\prime}$ min HC



SCB after $0^{\prime} \min$ HC

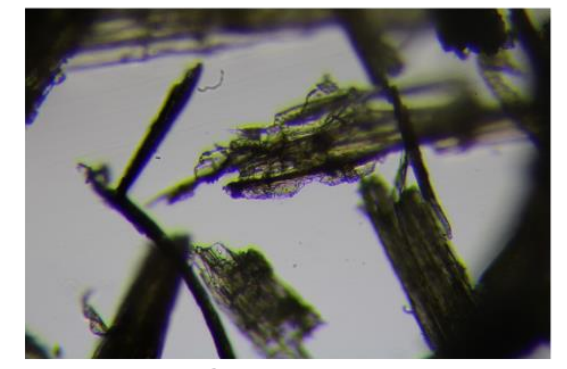

GS after $15 \min$ HC





GS after $60 \mathrm{~min}$ HC



Figure 3: Microscopy images showing the morphological changes in LCB due to HC treatment. (a) $200 \mathrm{X}$ magnified images of untreated and HC treated GS,

(b) $50 \mathrm{X}$ magnified images of untreated and HC treated SCB. Pre-treatment conditions: LCB starting concentration $=10 \mathrm{~g} / \mathrm{L}$, flow rate $=1.54 \mathrm{~m} / \mathrm{hr}$ and inlet pressure $=3.9$ barg . 
their degradation window is different with minimal overlaps ${ }^{74,75}$. However, the composition estimated from TGA did not agree with the composition obtained from the wet chemistry methods. Attempts to examine changes to the biomass composition upon HC treatment using TGA results were therefore inconclusive and not discussed here.

FTIR was performed with the untreated and HC treated solids and were compared in Figure 4. The details of the peaks and the corresponding wave numbers are listed in Table S2. All peaks marked to correspond the 3 main components of LCB have a lower intensity in the treated samples compared to their untreated counterparts. This indicates that cavitation pre-treatment affected all the fractions of the LCB. Particularly, with the HC treated GS samples, peaks 3 and 5 corresponding to lignin have reduced intensity compared to the untreated samples, indicating the loss of lignin in the samples with cavitation. Similarly, lignin bound hemicellulose (peak 4) and other named peaks corresponding to cellulose were also observed with a decreased intensity when compared to untreated GS. Likewise, considering the FTIR profiles of SCB samples, the intensity of the HC treated biomass for all the 3 fractions were lower than that of the initial untreated material, similar to that of GS samples. Specifically, peak 2, seen at $2918 \mathrm{~cm}^{-1}$ for the untreated sample had shifted to a lower wavenumber, $2900 \mathrm{~cm}^{-1}$ that corresponds to the $\mathrm{CH}_{2}$ group stretching. Nine passes through the $\mathrm{HC}$ device were enough to achieve this transition. Peak 3 , representing hemicellulose, decreased in intensity with cavitation time indicating that cavitation was affecting the hemicellulose fraction of SCB. Similarly, Peaks 4-6 corresponding to lignins were also observed with a reduced intensity with increase in cavitation time. Similar results with $\mathrm{HC}$ (using a venturi tube) and AC of corn stover powder (however in combination with sodium percarbonate) have been reported previously by Nakashima and coworkers ${ }^{55}$. More specifically, SCB pre-treatment using AC in combination with ozone and alkali have been reported in the past by Perrone et al in 2016. They reported a lower intensity of various chemical groups corresponding to different fractions of SCB upon pre-treatment ${ }^{76}$. This is in line with the observation in our study. In addition to monitoring changes in the biomass using FTIR, the lateral order index (LOI) which is the ratio of the transmittance at $1420 \mathrm{~cm}^{-1}$ (crystalline band) to $898 \mathrm{~cm}^{-1}$ (amorphous band) was determined. LOI is a measure of the relative crystallinity of the cellulose present in the biomass ${ }^{77}$. The calculated values for cavitated GS and SCB were found to be lower than their untreated counterparts ( 1.09 compared to $\sim 1.06$ ), which could potentially lead to improved cellulose hydrolysis during biogas generation.

XRD profiles of untreated and HC treated GS and SCB were recorded and the crystallinity, $\mathrm{Crl}$ of these samples was calculated. Minimal changes to $\mathrm{Crl}$ was observed for both the biomasses. For GS, the $\mathrm{Crl}$ of cavitated and untreated biomass fell in the range of 31.8-39.7\%, whereas in the case of SCB, this was $41.5-43.8 \%$ (see Figure S5). Similar results have been reported in the past by Madison et al in 



Figure 4: FTIR profiles showing the influence of HC treatment on the composition of (a) untreated and HC treated GS and (b) untreated and HC treated SCB. Pre-treatment conditions: $L C B$ starting concentration $=10 \mathrm{~g} / \mathrm{L}$, inlet flow rate $=1.54 \mathrm{~m}^{3} / \mathrm{hr}$, inlet pressure $=3.9 \mathrm{barg}$. 
$2017^{34}$ who observed insignificant changes to crystallinity of SCB upon HC (in a venturi tube) combined with lime pre-treatment.Even though their experiment spanned over 120 minutes, minimal and insignificant changes to crystallinity was observed.

\subsection{Liquid phase analysis}

A sample volume of the liquid fraction of $10 \mathrm{~g} / \mathrm{L}$ LCB slurry was separated from the solids via centrifugation and subjected to HPLC analysis. The liquid phase of the untreated GS samples when analysed, revealed, predominantly the presence of lactic acid and sorbitol (as a result of ensiling), in the concentration of $0.32 \mathrm{~g} / \mathrm{L}$ and $0.38 \mathrm{~g} / \mathrm{L}$ respectively. In addition, glucose at a concentration of 0.056 $\mathrm{g} / \mathrm{L}$ was also observed. With increase in $\mathrm{HC}$ time, the concentration of glucose gradually decreased to $0.043 \mathrm{~g} / \mathrm{L}$, and sorbitol gradually increased to $0.40 \mathrm{~g} / \mathrm{L}$. The acetic acid was found to be generated as number of passes through cavitation device increased (up to $1.48 \times 10^{-3} \mathrm{~g} / \mathrm{L}$ after 117 passes).

For SCB, the untreated feedstock's liquid phase comprised mainly of $\mathrm{C} 6$ sugars (glucose, fructose and galactose) in the concentration of $0.17 \mathrm{~g} / \mathrm{L}$ followed by arabinose at $0.044 \mathrm{~g} / \mathrm{L}$. Cellobiose and acetic acid were also present in concentrations at $3.76 \times 10^{-3} \mathrm{~g} / \mathrm{L}$ and $1.85 \times 10^{-3} \mathrm{~g} / \mathrm{L}$ respectively. With increase in number of passes through the cavitation device, a decrease in cellobiose concentration (to $\left.1.86 \times 10^{-3} \mathrm{~g} / \mathrm{L}\right)$, could be correlated to the increase in C6 sugars $(0.18 \mathrm{~g} / \mathrm{L})$ and acetic acid $\left(2.60 \times 10^{-3}\right.$ $\mathrm{g} / \mathrm{L}$ ) concentration. In addition, arabinose was found to slightly decrease with cavitation time (0.039 $\mathrm{g} / \mathrm{L})$. Following the trends of acetic acid production in both the cases, it is evident that these are produced from either the sugars in liquid phase directly, or indirectly from the solids fraction. This corresponds to the lower intensities of HC treated LCB as seen from the FTIR profiles (Figure 4).

Changes to the concentration of liquid phase products have been observed in the past upon LCB cavitation. For instance, Zielsinski et al. in $2019{ }^{78}$ reported that the soluble sugar concentration increased by $50 \mathrm{mg} / \mathrm{g}$ after 10 minutes HC of Sida hermaphrodita mixed with cattle slurry. No detailed analysis on the composition of the liquid phase was however reported.

\subsection{BMP measurements and kinetics}

CHNS analysis performed on the untreated feedstock was used to calculate the theoretical BMP. Based on these analyses, the empirical formula of GS was found to be $\mathrm{C}_{27.3} \mathrm{H}_{44.1} \mathrm{O}_{21.8} \mathrm{~N}$ and that of SCB was found to be $\mathrm{C}_{90} \mathrm{H}_{128.6} \mathrm{O}_{71.4} \mathrm{~N}$. The maximum BMP of these LCB were calculated using Buswell's equation ${ }^{59}$ and corresponded to $473.7 \mathrm{ml} \mathrm{CH}_{4} / \mathrm{g}$ VS and $437.9 \mathrm{ml} \mathrm{CH}_{4} / \mathrm{g}$ VS for GS and SCB respectively. The elemental analysis results and the theoretical BMP calculated based on these compositions for GS and SCB are summarised in Table 1. Theoretical BMP calculations based on reported elemental 
composition of GS was found to be in the range of $441-446 \mathrm{ml} \mathrm{CH}_{4} / \mathrm{g}$ VS. In case of SCB, the theoretical BMP was found to be in the range of $425-487 \mathrm{ml} \mathrm{CH}_{4} / \mathrm{g}$ VS.

\begin{tabular}{|c|c|c|c|c|c|c|c|}
\hline $\begin{array}{l}\text { LCB } \\
\text { type }\end{array}$ & Ash & $\% \mathrm{C}$ & $\% \mathbf{H}$ & $\% \mathbf{N}$ & $\% 0$ & $\begin{array}{l}\text { Calculated } \\
\text { maximum } \\
\text { BMP (ml } \\
\mathrm{CH}_{4} / \mathrm{g} \text { VS) }\end{array}$ & Reference \\
\hline GS & $8.2 \%$ & $44.4 \%$ & $6.0 \%$ & $1.9 \%$ & $39.2 \%$ & 473.7 & This study \\
\hline GS & & & & & & 446.3 & Wall et al., $2013^{79}$ \\
\hline GS & $7.5 \%$ & $43.0 \%$ & $5.8 \%$ & $1.6 \%$ & $42.0 \%$ & 441.2 & Nizami and Murphy., $2011^{80}$ \\
\hline GS & $7.5 \%$ & $43.0 \%$ & $5.8 \%$ & $1.6 \%$ & $42.0 \%$ & 441.2 & Thamsiriroj et al., $2012^{81}$ \\
\hline SCB & $4.1 \%$ & $45.5 \%$ & $5.4 \%$ & $0.6 \%$ & $44.1 \%$ & 437.9 & This study \\
\hline SCB & $5.2 \%$ & $43.8 \%$ & $6.0 \%$ & $1.7 \%$ & $43.4 \%$ & 436.4 & Munir et al., $2009^{82}$ \\
\hline SCB & $12.6 \%$ & $38.3 \%$ & $6.0 \%$ & $1.7 \%$ & $41.4 \%$ & 425.2 & Munir et al., $2009^{82}$ \\
\hline SCB & $3.2 \%$ & $45.5 \%$ & $6.0 \%$ & $0.2 \%$ & $45.2 \%$ & 446.5 & Channiwala and Parikh., $2002^{83}$ \\
\hline SCB & $11.3 \%$ & $44.8 \%$ & $5.4 \%$ & $0.4 \%$ & $38.2 \%$ & 486.9 & Channiwala and Parikh., $2002^{83}$ \\
\hline
\end{tabular}

Table 1: Comparison of elemental composition of SCB and GS reported in literature and the respective calculated maximum BMP using Buswell's equation against LCB used in this study.

The maximum standard deviation of the BMP of untreated GS was found to be $\pm 10 \mathrm{ml} \mathrm{CH}_{4} / \mathrm{g} \mathrm{VS}$ and that of the cavitation pre-treated GS was found to be $\pm 15 \mathrm{ml} \mathrm{CH}_{4} / \mathrm{g}$ VS. As most of the sample solids were used up for these duplicate experiments, the remaining solids were insufficient to prepare the slurry for replicate slurry BMP tests. It may however be reasonable to assume the standard deviation of slurry samples to be similar to the solids only samples. Variation between replicate cavitation runs, type of inoculum, particle size of LCB, type and cut of grass and ensiling time for GS may also influence BMP. However, influence of these parameters was not evaluated in this work.

Batch BMP tests were performed with either the obtained GS solids (Figure 5a) or GS slurry (Figure 5b). The corresponding fitted parameters for both the cases plotted in Figure 5 are shown in Table 2. The table on the goodness of the fits as obtained from GraphPad is shown in Table S3 and Table S4. In the case of GS solids, with increase in number of passes during $\mathrm{HC}$, an increase in $\mathrm{G}_{\max }$ of up to $12 \%$ until 9 passes was observed. The BMP increase observed after 36 passes was not statistically different from that observed after 9 passes, however after 117 passes the increase in BMP fell to $4 \%$. This could be attributed to the loss of organic matter from the solids due to over cavitation. In the case of GS slurry, it was seen that a maximum increase in BMP of $15 \%$ was obtained after 9 passes, beyond which a drop in BMP was observed. This decrease in BMP due to excess cavitation could be due to the presence of inhibitors such as short chain lignin and phenolics (lignin breakdown products) in the slurry samples. The presence of these inhibitors in the slurry samples could be expected because, as 
seen in the FTIR profiles of the HC treated GS solids (Figure 4a), a lower intensity of the lignin peaks was seen. The lignin lost from the solids during cavitation would enter the liquid phase and therefore could have contributed towards the inhibition. Similar effect of inhibitors on BMP due to over cavitation has been reported in the past by Langone et al in $2018^{41}$ and Garuti et al in $2018{ }^{32}$. A possible shift in the microbial population due the easily available sugars in the liquid phase may also contribute to a drop in BMP.

AD of GS for biomethane production has been reported in literature and pre-treatment methods other than cavitation ( $\mathrm{AC}$ or $\mathrm{HC}$ ) have been reported for improving the digestibility. In 2017, Jagadabhi et al. reported a BMP of $300 \mathrm{ml} \mathrm{CH} / \mathrm{g}$ VS from GS and managed to improve the BMP by $10 \%$ with the addition of micro and macro nutrients to the digester ${ }^{84}$. Rodriguez et al. in their review compiled information about small and medium scale AD plants operating with a wide range of feedstock for biomethane production ${ }^{85}$. They reported that a plant hosting a digester of $1600 \mathrm{~m}^{3}$ capacity in Klostermansfeld, Germany utilises GS as one of their feedstocks and pre-treats their feed stream via enzymatic hydrolysis to enhance the BMP by $12 \%$. The enhancement in BMP observed in the present work is in the similar range without using any external chemicals.

\begin{tabular}{|c|c|c|c|c|c|c|c|c|}
\hline Parameters & \multicolumn{4}{|c|}{ GS solids } & \multicolumn{4}{c|}{ GS slurry } \\
\hline Number of passes & $\mathbf{0}$ & $\mathbf{9}$ & $\mathbf{3 6}$ & $\mathbf{1 1 7}$ & $\mathbf{0}$ & $\mathbf{9}$ & $\mathbf{3 6}$ & $\mathbf{1 1 7}$ \\
\hline $\mathbf{G}_{\max }\left(\mathbf{m l ~ C H}_{\mathbf{4}} / \mathbf{g} \mathbf{~ V S}\right)$ & 282 & 321 & 307 & 293 & 369 & 433 & 342 & 420 \\
\hline $\mathbf{k}$ (day $^{-1}$ ) & 0.28 & 0.19 & 0.23 & 0.24 & 0.24 & 0.17 & 0.19 & 0.17 \\
\hline $\mathbf{G}_{\mathbf{0}}\left(\mathbf{m l ~ C H}_{4} / \mathbf{g} \mathbf{~ V S}\right)$ & 77.7 & 50.9 & 48.7 & 19.1 & 0 & 77 & 29 & 128 \\
\hline $\mathbf{t}_{\mathbf{0}}$ (days) & 3.0 & 4.0 & 2.0 & 1.5 & 0 & 2 & 1 & 3 \\
\hline $\mathbf{R}^{\mathbf{2}}$ & $>0.99$ & $>0.99$ & $>0.99$ & $>0.99$ & $>0.99$ & $>0.99$ & $>0.98$ & $>0.99$ \\
\hline \% increase in BMP & $0 \%$ & $12 \%$ & $8 \%$ & $4 \%$ & $0 \%$ & $15 \%$ & $-8 \%$ & $12 \%$ \\
\hline \% of $\mathbf{G}_{\text {th }}$ achieved & $60 \%$ & $68 \%$ & $65 \%$ & $62 \%$ & $78 \%$ & $91 \%$ & $72 \%$ & $89 \%$ \\
\hline
\end{tabular}

Table 2: Fitted parameters used in the first order model with time delay to describe the BMP profiles obtained from untreated and HC treated GS as shown in Figure 5. 



Figure 5: Influence of HC treatment on the BMP of untreated and treated GS. (a) BMP of the solids samples obtained before and after HC treatment subjected to digestion, (b) BMP of the slurry samples obtained before and after HC treatment subjected to digestion. Symbols denote experimental data and the lines denote fitted first order kinetic model with time delay. Pretreatment conditions: $L C B$ starting concentration $=10 \mathrm{~g} / \mathrm{L}$, inlet flow rate $=1.54 \mathrm{~m}^{3} / \mathrm{hr}$, inlet pressure $=3.9$ barg.

Similar to the GS samples, the maximum standard deviation of the BMP of untreated SCB was found to be $\pm 10 \mathrm{ml} \mathrm{CH}_{4} / \mathrm{g}$ VS and that of the cavitation pre-treated SCB was found to be $\pm 20 \mathrm{ml} \mathrm{CH}_{4} / \mathrm{g} \mathrm{VS}$. In the case of SCB feedstock, solids only and slurry were used as feedstock for BMP tests. The 
experimental and fitted BMP data for both the solids and slurry samples are shown in Figure 6 . The model parameters are shown in Table 3. The goodness of the fits for the solids and slurry BMP tests are given in Table S5 and Table S6. Unlike the GS samples, the SCB feedstock was not ensiled and hence did not have significant concentration of soluble products as discussed in Section 3.2. However, with increased pre-treatment time, the amount of C6 sugars and acetic acid increased which corresponded with the increase in BMP of the $\mathrm{HC}$ treated SCB slurry.

Untreated solids yielded $192 \mathrm{ml} \mathrm{CH}_{4} / \mathrm{g}$ VS whereas cavitated solids only did not improve the BMP. The untreated slurry on the other hand yielded $175 \mathrm{ml} \mathrm{CH} / \mathrm{g} \mathrm{VS}$ and the maximum yield of $290 \mathrm{ml} \mathrm{CH}_{4} / \mathrm{g}$ VS was observed with the slurry after 36 passes through the HC device which was higher than the untreated samples by $40 \%$. The untreated SCB slurry yielded $40 \%$ of the theoretical BMP whereas after 36 passes, $67 \%$ of theoretical yield was achieved. Further discussion on the number of passes relating to the energy requirement for pre-treatment as well as the associated gains for both the LCB's are discussed in the next section (Section 3.4).

The BMP of SCB reported in this work, falls in range within the BMP reported in earlier studies between 236-326 $\mathrm{ml} \mathrm{CH}_{4} / \mathrm{g}$ VS ${ }^{86}$. Badshah et al. compared a range of enzymatic and acid treatment combinations on SCB and determined that enzymatic hydrolysis of acid pre-treated SCB yielded a 16 $\%$ increase in BMP ${ }^{87}$. Further, the amount of inhibitors such as furfural and hydroxymethylfurfural usually formed during acid hydrolysis of biomass was produced in minimal quantities or in some cases not detected thereby not affecting the methanogenesis. Bolado-Rodríguez et al. reported the effect of autoclave treatment (with and without dilute $\mathrm{HCl}$ or $\mathrm{NaOH}$ ) and alkali peroxide pre-treatment on the BMP of $\mathrm{SCB}{ }^{88}$. BMP tests were also performed with the solids obtained from pre-treatment as well as the slurry obtained, similar to our work. When the untreated slurry was subjected to BMP tests $55 \%$ theoretical yield was achieved. The best yield was achieved with the slurry obtained from autoclave treatment that yielded $58 \%$ of theoretical BMP. In this work, HC pre-treatment was found to result more than $50 \%$ of theoretical BMP without using any external chemicals or enzymes. 



Figure 6: Influence of HC treatment on the BMP of untreated and treated SCB. (a) BMP of the solids samples obtained before and after $\mathrm{HC}$ treatment subjected to digestion, (b) BMP of the slurry samples obtained before and after HC treatment subjected to digestion. Symbols denote experimental data and the lines denote fitted first order kinetic model with time delay. Pretreatment conditions: $L C B$ starting concentration $=10 \mathrm{~g} / \mathrm{L}$, inlet flow rate $=1.54 \mathrm{~m}^{3} / \mathrm{hr}$, inlet pressure $=3.9$ barg. 


\begin{tabular}{|c|c|c|c|c|c|c|c|c|}
\hline \multirow{2}{*}{$\begin{array}{c}\text { Parameters } \\
\text { Number of passes }\end{array}$} & \multicolumn{4}{|c|}{ SCB solids } & \multicolumn{4}{|c|}{ SCB slurry } \\
\hline & 0 & 9 & 36 & 117 & 0 & 9 & 36 & 117 \\
\hline $\mathrm{G}_{\max }(\mathrm{ml} \mathrm{CH} / \mathrm{g} \mathrm{VS})$ & 192 & 186 & 188 & 198 & 175 & 229 & 290 & 256 \\
\hline$k\left(\right.$ day $\left.^{-1}\right)$ & 0.39 & 0.38 & 0.38 & 0.36 & 0.35 & 0.38 & 0.35 & 0.31 \\
\hline $\mathrm{G}_{0}(\mathrm{ml} \mathrm{CH} / \mathrm{g}$ VS) & 63.8 & 66.4 & 60.8 & 70.2 & 48.9 & 141.1 & 167.1 & 95.1 \\
\hline$t_{0}$ (days) & 6.5 & 6.5 & 6.5 & 6.5 & 5.5 & 7.5 & 7.5 & 6.5 \\
\hline $\mathbf{R}^{2}$ & $>0.99$ & $>0.99$ & $>0.99$ & $>0.99$ & $>0.99$ & $>0.99$ & $>0.99$ & $>0.99$ \\
\hline \% increase in BMP & $0 \%$ & $-3 \%$ & $-2 \%$ & $3 \%$ & $0 \%$ & $24 \%$ & $40 \%$ & $32 \%$ \\
\hline$\%$ of $G_{\text {th }}$ achieved & $44 \%$ & $43 \%$ & $43 \%$ & $45 \%$ & $40 \%$ & $53 \%$ & $67 \%$ & $59 \%$ \\
\hline
\end{tabular}

Table 3: Fitted parameters used in the first order model with time delay to describe the BMP profiles obtained from untreated and $\mathrm{HC}$ treated SCB as shown in Figure 6.

The solid only BMP did not yield any significant improvement in biomethane production for both GS and SCB. However, the slurry samples in both the cases yielded an effective enhancement in biomethane production. Therefore, the obtained model parameters from the slurry BMP tests is further discussed in this section. Figure 7 shows the influence of number of passes through the HC device on $\mathrm{k}$ and $\mathrm{t}_{0}$ for both GS and SCB slurries. An increase in BMP lag time upon HC treatment when compared to the untreated slurries was observed in both the cases. Considering k, for the GS slurries, the rate dropped from 0.244 day $^{-1}$ with untreated samples to $0.174 \pm 0.005$ day $^{-1}$ with the HC treated samples. In the case of SCB slurries, the rate was found to be around $0.348 \pm 0.024$ day $^{-1}$ with no significant change upon cavitation. Nevertheless, a difference in $t_{0}$ and $k$ between untreated and cavitated samples were seen, an enhancement in BMP was observed.

The crux of this work is to determine the influence of vortex based HC pre-treatment on the BMP of the feedstock. To capture this, the yield of biomethane as the ratio of $G_{\max }$ to theoretical BMP was calculated for each operating condition and feedstock and plotted against number of passes through the $\mathrm{HC}$ device as shown in Figure 8. In the same figure, the effect of number of passes on $\mathrm{G}_{0}$ is also presented. It is evident from this figure that 9 passes through the device showed a maximum possible biomethane yield for GS slurry amongst the investigated conditions. In the case of SCB however, the maximum possible yield was achieved after 36 passes. A $66 \%$ yield was achieved after 36 passes compared to $40 \%$ from the untreated SCB slurry. However, the energy gain calculations (as discussed in section 3.4) revealed that the maximum energy gain was possible with 9 passes (at $52 \%$ yield). Therefore, 9 passes through the device was determined to be the optimum for SCB as well. $G_{0}$, determined from fitting the data to the model was found to follow the same trend as $G_{\max }$. 




Figure 7: Effect of number of passes through $\mathrm{HC}$ device on the biomethane generation rate $(\mathrm{k})$ and lag time $\left(t_{0}\right)$ obtained from fitting the LCB slurry BMP data to the developed first order model.

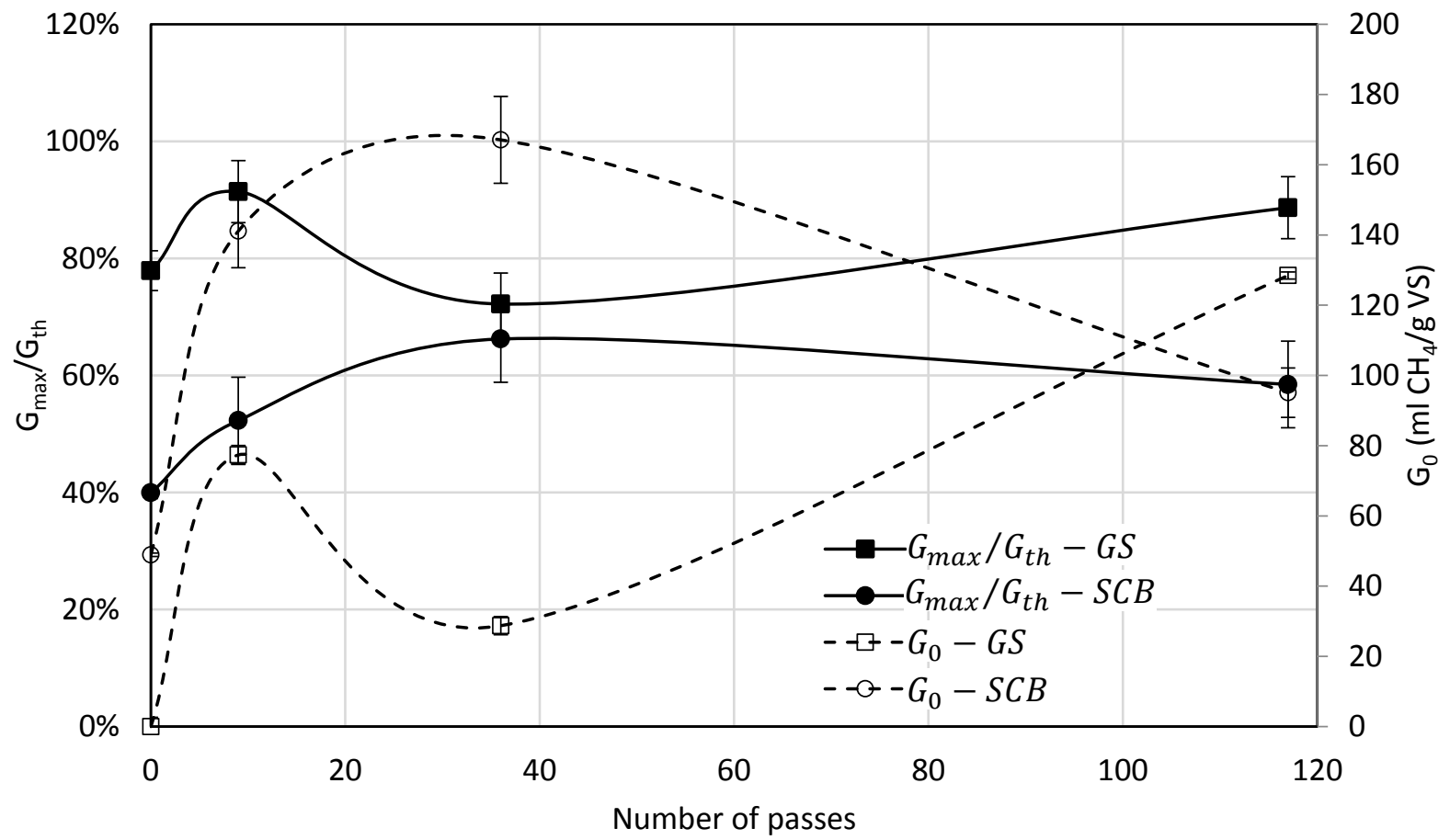

Figure 8: Influence of number of passes through $\mathrm{HC}$ device on the biomethane yield and $\mathrm{G}_{0}$ obtained from fitting BMP data from GS and SCB slurries to the developed first order model. Theoretical BMP of GS and SCB used for the calculations were $473.7 \mathrm{ml} \mathrm{CH}_{4} / \mathrm{g}$ VS and $437.9 \mathrm{ml} \mathrm{CH}_{4} / \mathrm{g}$ VS respectively. 


\subsection{Energy consumption of and net energy gain by HC based LCB pre-treatment}

It is evident from the presented results that vortex based HC pre-treatment of LCB was effective in enhancing the BMP of both the feedstocks. The vortex based cavitation device used in this study has no moving parts and can be scaled up to translate the LCB pre-treatment performance observed on a bench scale. The ease of retrofitting this $\mathrm{HC}$ device to existing feed lines of an AD plant is another added advantage. It is therefore worthwhile to examine energy requirements for cavitation pretreatment and overall economics of using it for enhancing biogas generation. A typical arrangement of vortex based LCB pre-treatment for AD is shown in Figure 9.

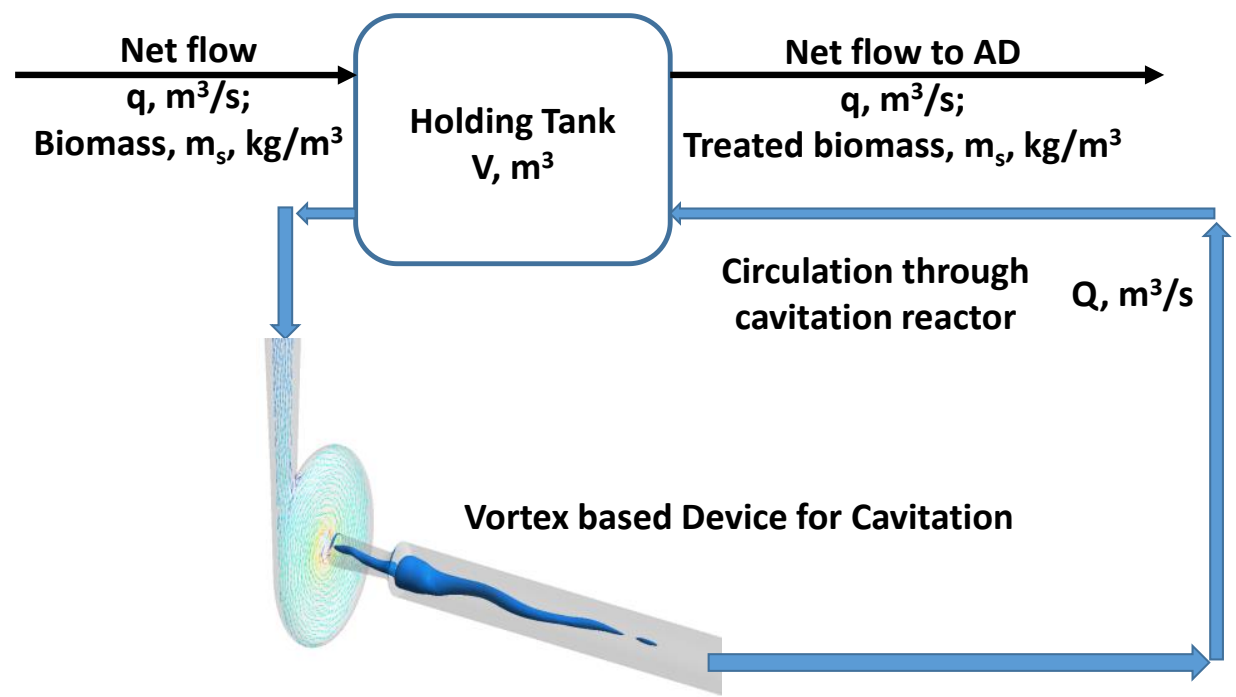

Figure 9: Proposed pre-treatment using vortex based hydrodynamic cavitation

$\mathrm{HC}$ pre-treatment does not require any chemicals. Therefore, operating cost of $\mathrm{HC}$ based pretreatment is the cost of energy required to pump the biomass slurry through cavitation device. The cost of HC pre-treatment is directly proportional to the number of passes required for the pretreatment which is same as the ratio of flow rate through cavitation device $(Q)$ to the net flow $(q)$. The energy required for pre-treating a ton of biomass can therefore be written as:

$E_{\text {pre-treatment }}=\frac{\Delta P Q}{3600 q m_{s} \eta} \frac{k W h}{\text { ton of biomass }}$

where $\Delta \mathrm{P}$ is pressure drop across vortex based cavitation device, $\mathrm{Pa} ; \mathrm{Q}$ is flow rate through cavitation device, $\mathrm{m}^{3} / \mathrm{s}$; $q$ is flow rate of slurry to $A D, \mathrm{~m}^{3} / \mathrm{s}, \mathrm{m}_{\mathrm{s}}$ is concentration of biomass in feed slurry, $\mathrm{kg} / \mathrm{m}^{3}$ and $\eta$ is efficiency of a pump used to circulate slurry through cavitation device. With pre-treatment, the overall digestibility improves and therefore additional energy generated because of the pretreatment may be estimated as: 
$E_{\text {gained by pre-treatment }}=\Delta H_{\text {cal }}\left(\left[G_{\text {max }}\right]_{\text {pre-treated }}-\left[G_{\text {max }}\right]_{\text {un-treated }}\right) \frac{k W h}{\text { ton of biomass }}$

where $\Delta H_{\text {cal }}$ is calorific value of methane, $\mathrm{kWh} / \mathrm{m}^{3}$ of methane $\left(\sim 10 \mathrm{kWh} / \mathrm{m}^{3}\right)$ and $\mathrm{G}_{\max }$ is maximum BMP, $\mathrm{m}^{3} /$ ton.

Considering the experimental results obtained in this work [pressure drop as $3.9 \mathrm{barg}, \mathrm{Q} / \mathrm{q}=9$ ] and assuming pump efficiency as 0.7 , the energy required for $\mathrm{HC}$ pre-treatment is shown in Figure 10 as a function of solid (biomass) loading of the slurry. Obviously, as the solids loading increases, the net flow through cavitation device decreases and therefore energy required for pre-treatment decreases. The results indicate that for $1 \%$ biomass loading, the energy required is nearly $140 \mathrm{kWh} /$ ton of biomass. It has to be noted that the energy required for pre-treatment is primarily the function of number of passes and solid loading and not a function of type of biomass. The energy consumption required for the $\mathrm{HC}$ pre-treatment considered here compares very favourably with the earlier published results (440-660 kWh/ton total solids, Langone et al. ${ }^{41} ; 280 \mathrm{kWh} /$ ton total solids reported by Zieliński et al. ${ }^{78}$ ) even at low biomass loading of $1 \%$. The quoted energy consumption for pre-treatment does not include energy required for milling the biomass prior to making slurry. It should be noted that in practice, one can use biomass slurry of $10 \%$ solid loading without incurring clogging for many types of biomasses. For higher biomass loading such as $10 \%$, the energy consumption of HC pre-treatment is very small ( $14 \mathrm{kWh} /$ ton of biomass) compared to the additional energy generated through enhanced biogas. The additional energy gains due to enhanced biogas generation for GS and SCB were calculated using the experimental data obtained in this work (for 9 passes) and Equation (1) as $625 \mathrm{kWh} / \mathrm{ton}$ of biomass and $~ 517 \mathrm{kWh} /$ ton of biomass respectively. Thus, vortex based HC pre-treatment (with 9 passes) will result in additional revenue of $\sim £ 60 /$ ton TS of GS and $\sim £ 50 /$ ton TS of SCB assuming the price of energy as 10 pence/ kWh.

It is expected that the increased revenue generated from enhanced biomethane production using $\mathrm{HC}$ pre-treatment will improve the overall economics of biomass valorisation. If the pre-treatment and $A D$ is coupled with biorefining the residual cellulose from $A D$ digestate to value added chemicals, overall economic viability will further enhance. The HC pre-treatment using vortex based devices can be further enhanced by variety of ways: for example by introducing acid or alkali or hydrogen peroxide at the eye of the vortex to explore possible synergy between cavitation and additives; or by eliminating the need for milling: the vortex based devices do not use small constrictions and therefore may be used for pre-treating unchopped biomass slurry, especially at a larger scale. We hope that this work stimulates further research on harnessing hydrodynamic cavitation for pre-treatment of LCB. 


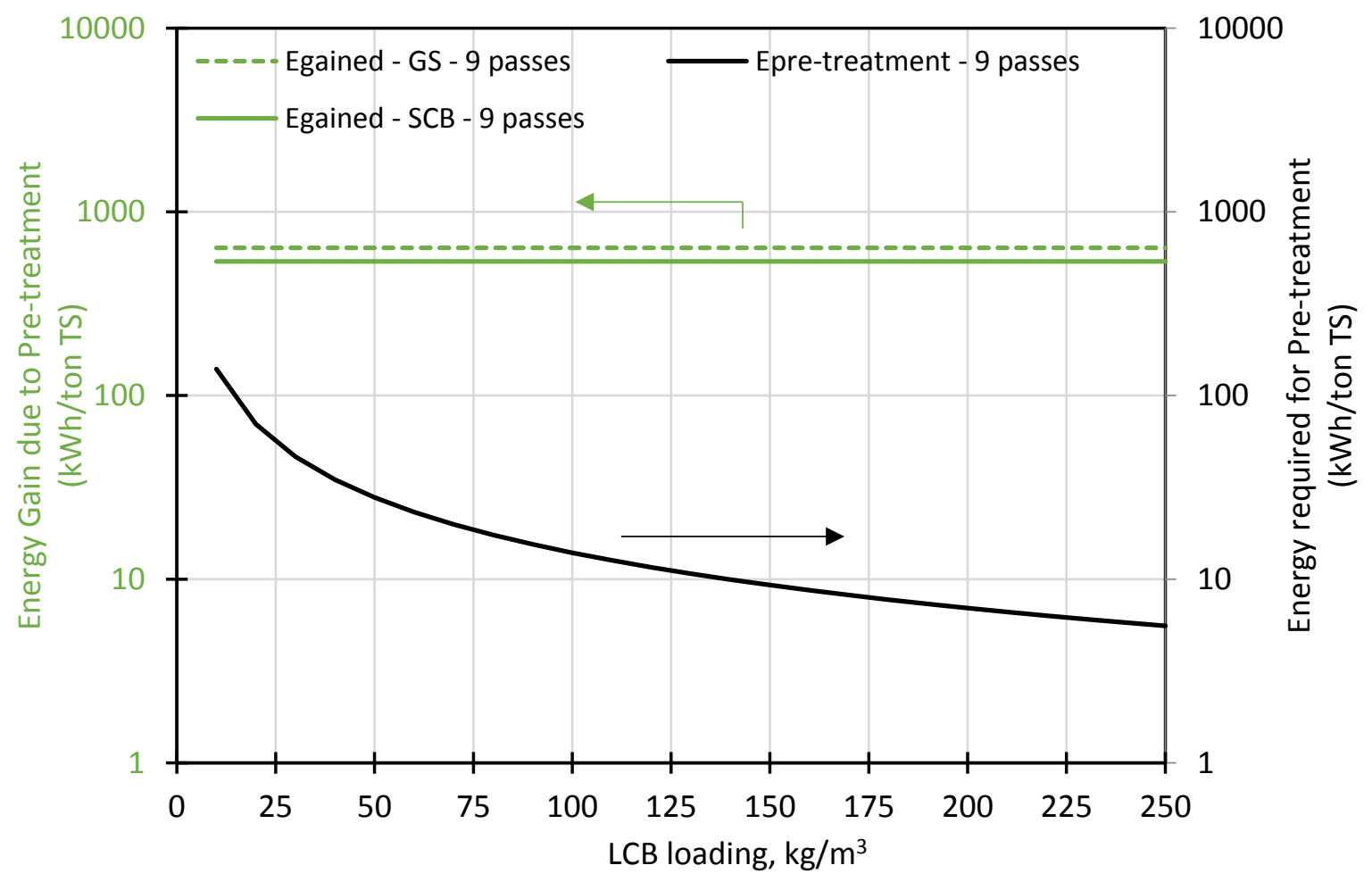

Figure 10: Energy required for (continuous line corresponding to the right $y$-axis) and gained by vortex based HC pre-treatment of GS (dotted line corresponding to the left $y$-axis) and SCB (continuous line corresponding to the left $y$-axis) after 9 passes.

\section{Conclusion}

In this work we have reported the use of a vortex based cavitation device for the pre-treatment of two most abundantly available LCB, namely GS and SCB. The vortex based HC pre-treatment was shown to cause physico - chemical changes to the biomass slurry. This was evident from various structural, morphological and compositional analysis carried out using microscope, FTIR and TGA, as well as in liquid phase analysis using HPLC. The HC pre-treatment lead to significant increase in BMP (up to $15 \%$ for GS and $40 \%$ for SCB). The two stage first order kinetic model was able to describe the experimentally measured BMP data. The digestion rate constant was not found to be very sensitive to the number of passes through cavitation device. The maximum BMP $\left(G_{\max }\right)$ however showed a maxima with respect to number of passes (9 passes for GS and 36 passes for SCB). Energy required for the vortex based HC pre-treatment was found to be quite small compared to the previously reported values. The maximum net gain in energy (energy gain via enhanced biogas generation - energy required for HC pre-treatment) was found to be $\sim 600 \mathrm{kWh} /$ ton for GS and $\sim 500 \mathrm{kWh} /$ ton for SCB at number of passes equal to 9. The approach and results presented in this work will be useful in harnessing hydrodynamic cavitation for enhancing biogas generation from anaerobic digestion and eventually lead to AD based biorefinery. 


\section{Notations}

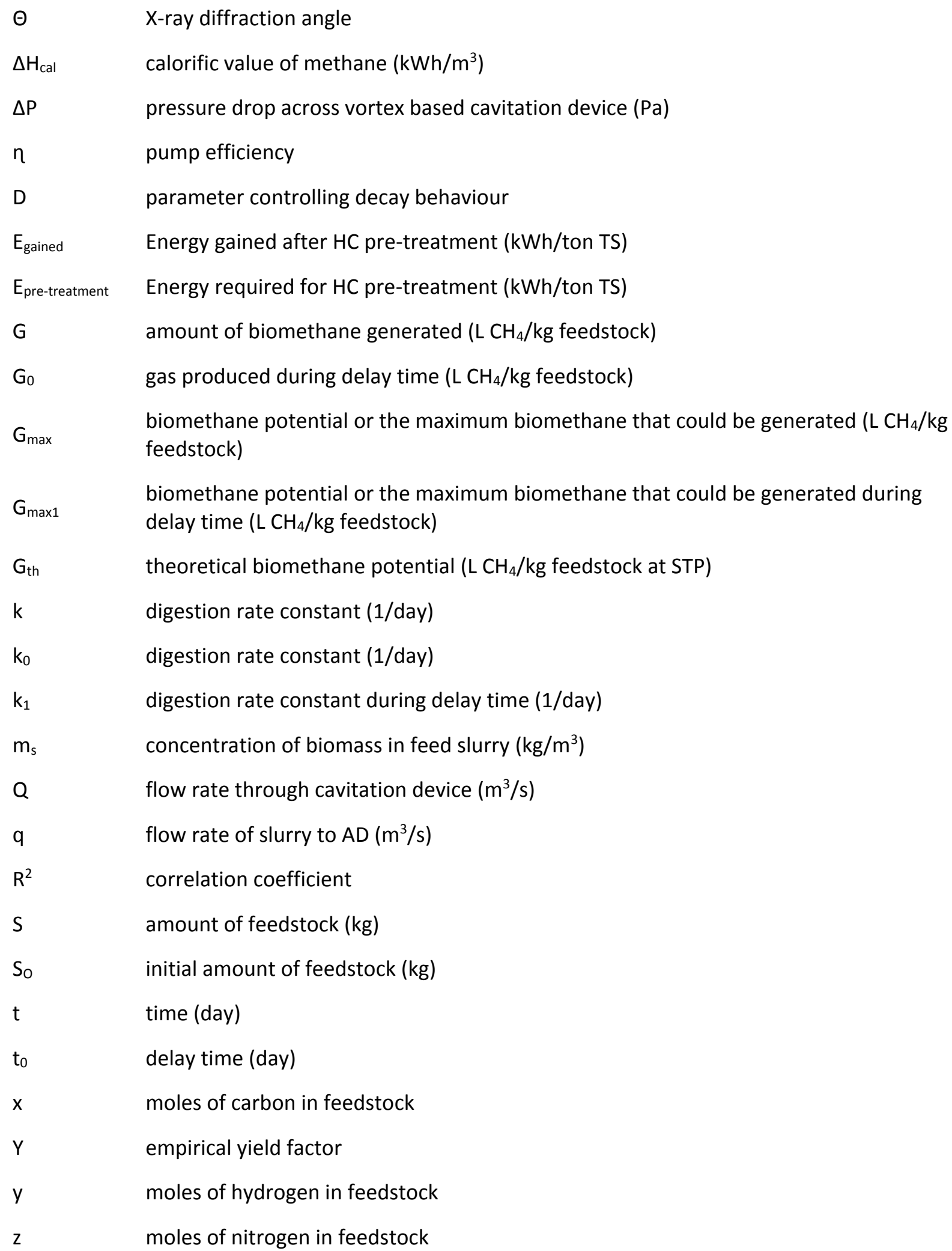




\section{Acronyms:}

\begin{tabular}{|c|c|}
\hline$A C$ & Acoustic cavitation \\
\hline$A D$ & Anaerobic digestion \\
\hline AFBI & Agri Food and Biosciences Institute, Belfast \\
\hline AMPTS & Automatic methane potential test system \\
\hline BMP & Biochemical methanation potential \\
\hline COD & Chemical oxygen demand \\
\hline $\mathrm{Crl}$ & Crystallinity index \\
\hline DTG & Derivative thermogravimetry \\
\hline FTIR & Fourier-transform-infrared spectroscopy \\
\hline GS & Grass silage \\
\hline $\mathrm{HC}$ & Hydrodynamic cavitation \\
\hline HPLC-RI & High-performance liquid chromatography-refractive index \\
\hline IEA & International Energy Agency \\
\hline LCB & Lignocellulosic biomass \\
\hline LOI & Lateral order index \\
\hline NPT & Nova pangaea technologies \\
\hline ROS & Reactive oxygen species \\
\hline SCB & Sugarcane bagasse \\
\hline TGA & Thermogravimetry analysis \\
\hline TPES & Total primary energy supply statistics \\
\hline TS & Total solids \\
\hline VS & Volatile solids \\
\hline VSI & Vasantdada sugar institute, Pune \\
\hline XRD & X-ray diffraction \\
\hline
\end{tabular}

\section{Acknowledgements:}

The authors gratefully acknowledge funding support from the start-up grant no. G1013CHM from Queen's University Belfast, United Kingdom; Invest NI CASE project CAVICAT (grant no. R3947CCE) and Innovate UK, BBSRC UK and Department of Biotechnology, Government of India for funding the vWa Project (grant no. R1954CCE). Authors would like to gratefully acknowledge our vWa project partners (NPT and VSI) for sharing the details of compositional analysis of sugarcane bagasse. Authors would like to acknowledge Dr Chris Johnston and Dr Gary Lyons of AFBI for sharing grass silage, inoculum and BMP measurement (AMPTS II) facilities and Mr. Michael Wills of AFBI for his support around operating the AMPTS II. Authors would also like to acknowledge our vWa project partner, Dhampur Sugar Mills for sharing sugarcane bagasse. 


\section{Supplementary information}

The supplementary information has details on

(i) previously reported AC and HC based pre-treatment of a variety of LCB's

(ii) photographs and description of the $\mathrm{HC}$ rig used in the experiments,

(iii) details on characterisation of substrates before and after cavitation using TGA, FTIR, composition analysis and XRD and

(iv) tables on statistical analysis.

\section{Conflict of Interest:}

One of the authors (VVR) is a founder director of Vivira Process Technologies Pvt. Ltd. which commercially offers cavitation devices used in this study.

\section{References}

1. Himmel, M. E.; Ding, S.; Johnson, D. K.; Adney, W. S.; Nimlos, M. R.; Brady, J. W.; Foust, T. D. Biomass Recalcitrance: Engineering Plants and Enzymes for Biofuels Production. Science 2007, 315, 804.

2. Chen, H.; Fu, X. Industrial technologies for bioethanol production from lignocellulosic biomass. Renew. Sust. Energ. Rev. 2016, 57, 468.

3. Du, L.; Shao, Y.; Sun, J.; Yin, G.; Du, C.; Wang, Y. Electrocatalytic valorisation of biomass derived chemicals. Catal. Sci. Technol. 2018, 8, 3216.

4. Güngören Madenoğlu, T.; Sağlam, M.; Yüksel, M.; Ballice, L. Hydrothermal gasification of biomass model compounds (cellulose and lignin alkali) and model mixtures. J. Supercrit. Fluids 2016, 115, 79.

5. Hamad, M. A.; Radwan, A. M.; Heggo, D. A.; Moustafa, T. Hydrogen rich gas production from catalytic gasification of biomass. Renew. Energ. 2016, 85, 1290.

6. Wiselogel, A.; Tyson, S.; Johnson, D. Chapter 6 - Biomass Feedstock Resources and Composition. In Handstbook on Bioethanol - Production and Utilization; Wyman, C., Ed.; Routledge: New York, 1996.

7. Yang, L.; Xu, F.; Ge, X.; Li, Y. Challenges and strategies for solid-state anaerobic digestion of lignocellulosic biomass. Renew. Sust. Energ. Rev. 2015, 44, 824.

8. Parsell, T.; Yohe, S.; Degenstein, J.; Jarrell, T.; Klein, I.; Gencer, E.; Hewetson, B.; Hurt, M.; Kim, J. I.; Choudhari, H.; Saha, B.; Meilan, R.; Mosier, N.; Ribeiro, F.; Delgass, W. N.; Chapple, C.; Kenttämaa, H. I.; Agrawal, R.; Abu-Omar, M. A synergistic biorefinery based on catalytic conversion of lignin prior to cellulose starting from lignocellulosic biomass. Green Chem. 2015, 17, 1492.

9. Jiang, L.; Hu, S.; Wang, Y.; Su, S.; Sun, L.; Xu, B.; He, L.; Xiang, J. Catalytic effects of inherent alkali and alkaline earth metallic species on steam gasification of biomass. Int. J. Hydrog. Energy. 2015, 40, 15460. 
10. Luska, K. L.; Migowski, P.; Leitner, W. Ionic liquid-stabilized nanoparticles as catalysts for the conversion of biomass. Green Chem. 2015, 17, 3195.

11. Sawatdeenarunat, C.; Surendra, K. C.; Takara, D.; Oechsner, H.; Khanal, S. K. Anaerobic digestion of lignocellulosic biomass: Challenges and opportunities. Bioresour. Technol. 2015, 178, 178.

12. Li, W., Xu, Z., Zhang, T., Li, G., Jameel, H., Chang, H., Ma,L. Catalytic Conversion of Biomass-derived Carbohydrates into 5-Hydroxymethylfurfural using a Strong Solid Acid Catalyst in Aqueous $\gamma$ Valerolactone. BioResources 2016, 11, 5839.

13. Singh, R.; Krishna, B. B.; Mishra, G.; Kumar, J.; Bhaskar, T. Strategies for selection of thermochemical processes for the valorisation of biomass. Renew. Energ. 2016, 98, 226.

14. Liu, B.; Zhang, Z. Catalytic Conversion of Biomass into Chemicals and Fuels over Magnetic Catalysts. ACS Catal. 2016, 6, 326.

15. Priecel, P.; Perez Mejia, J. E.; Carà, P. D.; Lopez-Sanchez, J. CHAPTER 8 Microwaves in the Catalytic Valorisation of Biomass Derivatives. In Sustainable Catalysis for Biorefineries; The Royal Society of Chemistry: 2018.

16. Da Costa Gomez, C. 1 - Biogas as an energy option: an overview. In The Biogas Handbook; Wellinger, A., Murphy, J. and Baxter, D., Eds.; Woodhead Publishing: 2013.

17. Banks, C. Renewable energy from crop and agro wastes. http://www.cropgen.soton.ac.uk/deliverables/CROPGEN PFAR2007.pdf (accessed Jan/04, 2019).

18. Rao, P. V.; Baral, S. S.; Dey, R.; Mutnuri, S. Biogas generation potential by anaerobic digestion for sustainable energy development in India. Renew. Sust. Energ. Rev. 2010, 14, 2086.

19. Ministry of Petroleum and Natural Gas, Government of India Petroleum Minister launches SATAT initiative to promote Compressed Bio-Gas as an alternative, green transport fuel. http://pib.nic.in/newsite/PrintRelease.aspx?relid=183842 (accessed 31Jan, 2019).

20. Mao, C.; Feng, Y.; Wang, X.; Ren, G. Review on research achievements of biogas from anaerobic digestion. Renew. Sust. Energ. Rev. 2015, 45, 540.

21. Amha, Y. M.; Anwar, M. Z.; Brower, A.; Jacobsen, C. S.; Stadler, L. B.; Webster, T. M.; Smith, A. L. Inhibition of anaerobic digestion processes: Applications of molecular tools. Bioresour. Technol. 2018, 247, 999.

22. Chen, Y.; Cheng, J. J.; Creamer, K. S. Inhibition of anaerobic digestion process: A review. Bioresour. Technol. 2008, 99, 4044.

23. Surendra, K. C.; Sawatdeenarunat, C.; Shrestha, S.; Sung, S.; Khanal, S. K. Anaerobic DigestionBased Biorefinery for Bioenergy and Biobased Products. Ind. Biotechnol. 2015, 11, 103.

24. Paudel, S. R.; Banjara, S. P.; Choi, O. K.; Park, K. Y.; Kim, Y. M.; Lee, J. W. Pretreatment of agricultural biomass for anaerobic digestion: Current state and challenges. Bioresour. Technol. 2017, 245, 1194.

25. Silverstein, R. A. A comparison of chemical pretreatment methods for converting cotton stalks to ethanol, North Carolina State University, 2004. 
26. Haque, N.; Somerville, M. Techno-Economic and Environmental Evaluation of Biomass Dryer. Procedia. Eng. 2013, 56, 650.

27. Priyanto, D. E.; Ueno, S.; Kasai, H.; Mae, K. Rethinking the Inherent Moisture Content of Biomass: Its Ability for Milling and Upgrading. ACS. Sustain. Chem. Eng. 2018, 6, 2905.

28. Miao, Z.; Grift, T. E.; Hansen, A. C.; Ting, K. C. Energy requirement for comminution of biomass in relation to particle physical properties. Ind. Crop. Prod. 2011, 33, 504.

29. Sun, Y.; Cheng, J. Hydrolysis of lignocellulosic materials for ethanol production: a review. Bioresour. Technol. 2002, 83, 1.

30. Agbor, V. B.; Cicek, N.; Sparling, R.; Berlin, A.; Levin, D. B. Biomass pretreatment: Fundamentals toward application. Biotechnol. Adv. 2011, 29, 675.

31. Abrahamsson, L. Improving methane production using hydrodynamic cavitation as pre-treatment, Linköping University, Sweden, 2015.

32. Garuti, M.; Langone, M.; Fabbri, C.; Piccinini, S. Monitoring of full-scale hydrodynamic cavitation pretreatment in agricultural biogas plant. Bioresour. Technol. 2018, 247, 599.

33. Zieliński, M.; Dębowski, M.; Kisielewska, M.; Nowicka, A.; Rokicka, M.; Szwarc, K. Comparison of Ultrasonic and Hydrothermal Cavitation Pretreatments of Cattle Manure Mixed with Straw Wheat on Fermentative Biogas Production. Waste. Biomass. Valorization. 2017, 10, 747.

34. Madison, M. J.; Coward-Kelly, G.; Liang, C.; Karim, M. N.; Falls, M.; Holtzapple, M. T. Mechanical pretreatment of biomass - Part I: Acoustic and hydrodynamic cavitation. Biomass. Bioenergy. 2017, 98, 135 .

35. Terán Hilares, R.; de Almeida, G. F.; Ahmed, M. A.; Antunes, F. A. F.; da Silva, S. S.; Han, J.; Santos, J. C. d. Hydrodynamic cavitation as an efficient pretreatment method for lignocellulosic biomass: A parametric study. Bioresour. Technol. 2017, 235, 301.

36. Patil, P. N.; Gogate, P. R.; Csoka, L.; Dregelyi-Kiss, A.; Horvath, M. Intensification of biogas production using pretreatment based on hydrodynamic cavitation. Ultrason. Sonochem. 2016, 30, 79.

37. Kim, I.; Lee, I.; Jeon, S. H.; Hwang, T.; Han, J. Hydrodynamic cavitation as a novel pretreatment approach for bioethanol production from reed. Bioresour. Technol. 2015, 192, 335.

38. Baxi, P. B.; Pandit, A. B. Using cavitation for delignification of wood. Bioresour. Technol. 2012, 110, 697.

39. Lee, I.; Han, J. The effects of waste-activated sludge pretreatment using hydrodynamic cavitation for methane production. Ultrason. Sonochem. 2013, 20, 1450.

40. Saharan, V. K.; Pinjari, D. V.; Gogate, P. R.; Pandit, A. B. Chapter 3 - Advanced Oxidation Technologies for Wastewater Treatment: An Overview. In Industrial Wastewater Treatment, Recycling and Reuse; Ranade, V. V., Bhandari, V. M., Eds.; Butterworth-Heinemann: Oxford, 2014. 
41. Langone, M.; Soldano, M.; Fabbri, C.; Pirozzi, F.; Andreottola, G. Anaerobic Digestion of Cattle Manure Influenced by Swirling Jet Induced Hydrodynamic Cavitation. Appl. Biochem. Biotechnol. 2018, $184,1200$.

42. CAVIMAX http://www.cavimax.co.uk/ (accessed 23Jan, 2019).

43. ARISDYNE http://www.arisdyne.com/ (accessed 23Jan, 2019).

44. BioBANG https://www.biobang.com/en/home-page (accessed 23Jan, 2019).

45. VIVIRA Process Technologies Ltd http://www.vivira.in/ (accessed 05Feb, 2019).

46. Department of Agriculture, Environment and Rural Affairs - NI Statistics on crop production 1981 onwards. https://www.daera-ni.gov.uk/publications/statistics-crop-production-form-1981 (accessed 06Feb, 2019).

47. Ministry of Agriculture \& Farmers Welfare, Government of India Department of Agriculture, Cooperation \& Farmers Welfare Annual Report 2016-17. http://agricoop.nic.in/sites/default/files/Krishi\%20AR\%202017-18-1\%20for\%20web.pdf (accessed 31Jan, 2019).

48. Sarvothaman, V. P.; Nagarajan, S.; Ranade, V. V. Treatment of Solvent-Contaminated Water Using Vortex-Based Cavitation: Influence of Operating Pressure Drop, Temperature, Aeration, and Reactor Scale. Ind. Eng. Chem. Res. 2018, 57, 9292.

49. Ranade, V. V.; Kulkarni, A. A.; Bhandari, V. M. US9422952B2, 2016.

50. Suryawanshi, P. G.; Bhandari, V. M.; Sorokhaibam, L. G.; Ruparelia, J. P.; Ranade, V. V. Solvent degradation studies using hydrodynamic cavitation. Environ. Prog. Sustain. Energy. 2017, 37, 295.

51. Sivakumar, M.; Pandit, A. B. Wastewater treatment: a novel energy efficient hydrodynamic cavitational technique. Ultrason. Sonochem. 2002, 9, 123.

52. Barik, A. J.; Gogate, P. R. Hybrid treatment strategies for 2,4,6-trichlorophenol degradation based on combination of hydrodynamic cavitation and AOPs. Ultrason. Sonochem. 2018, 40, 383.

53. Rajoriya, S.; Bargole, S.; George, S.; Saharan, V. K. Treatment of textile dyeing industry effluent using hydrodynamic cavitation in combination with advanced oxidation reagents. J. Hazard. Mater. 2018, 344, 1109.

54. Hasani Zonoozi, M.; Moghaddam, M. R. A.; Maknoon, R. Investigation of HRT effects on membrane fouling in sequencing batch membrane bioreactor with respect to batch filtration mode. Environ. Prog. Sustain. Energy. 2017, 36, 1785.

55. Nakashima, K.; Ebi, Y.; Shibasaki-Kitakawa, N.; Soyama, H.; Yonemoto, T. Hydrodynamic Cavitation Reactor for Efficient Pretreatment of Lignocellulosic Biomass. Ind. Eng. Chem. Res. 2016, 55, 1866.

56. Franco, R. T.; Buffière, P.; Bayard, R. Co-ensiling of cattle manure before biogas production: Effects of fermentation stimulants and inhibitors on biomass and methane preservation. Renew. Energ. 2018, $121,315$. 
57. Kljun, A.; Benians, T. A. S.; Goubet, F.; Meulewaeter, F.; Knox, J. P.; Blackburn, R. S. Comparative Analysis of Crystallinity Changes in Cellulose I Polymers Using ATR-FTIR, X-ray Diffraction, and Carbohydrate-Binding Module Probes. Biomacromolecules 2011, 12, 4121.

58. Strömberg, S.; Nistor, M.; Liu, J. Towards eliminating systematic errors caused by the experimental conditions in Biochemical Methane Potential (BMP) tests. Waste. Manag. 2014, 34, 1939.

59. Nielfa, A.; Cano, R.; Fdz-Polanco, M. Theoretical methane production generated by the codigestion of organic fraction municipal solid waste and biological sludge. Biotechnol. Rep. 2015, 5, 14.

60. Thomsen, S. T.; Spliid, H.; Østergård, H. Statistical prediction of biomethane potentials based on the composition of lignocellulosic biomass. Bioresour. Technol. 2014, 154, 80.

61. Strömberg, S.; Nistor, M.; Liu, J. Early prediction of Biochemical Methane Potential through statistical and kinetic modelling of initial gas production. Bioresour. Technol. 2015, 176, 233.

62. Beuvink, J. M. W.; Kogut, J. Modeling gas production kinetics of grass silages incubated with buffered ruminal fluid1. J. Animal. Sci. 1993, 71, 1041.

63. Graphpad Prism 8 - Analysis and graphing software. https://www.graphpad.com/ (accessed 05Apr, 2019).

64. Chen, W.; Tu, Y.; Sheen, H. Impact of dilute acid pretreatment on the structure of bagasse for bioethanol production. Int. J. Energy Res. 2010, 34, 265.

65. Lyons, G.; Carmichael, E.; McRoberts, C.; Aubry, A.; Thomson, A.; Reynolds, C. K. Prediction of Lignin Content in Ruminant Diets and Fecal Samples Using Rapid Analytical Techniques. J. Agric. Food. Chem. 2018, 66, 13031.

66. Xie, S.; Frost, J. P.; Lawlor, P. G.; Wu, G.; Zhan, X. Effects of thermo-chemical pre-treatment of grass silage on methane production by anaerobic digestion. Bioresour. Technol. 2011, 102, 8748.

67. Schwarz, D.; Dörrstein, J.; Kugler, S.; Schieder, D.; Zollfrank, C.; Sieber, V. Integrated biorefinery concept for grass silage using a combination of adapted pulping methods for advanced saccharification and extraction of lignin. Bioresour. Technol. 2016, 216, 462.

68. Niemi, P.; Pihlajaniemi, V.; Rinne, M.; Siika-aho, M. Production of sugars from grass silage after steam explosion or soaking in aqueous ammonia. Ind. Crop. Prod. 2017, 98, 93.

69. Prapinagsorn, W.; Sittijunda, S.; Reungsang, A. Co-Digestion of Napier Grass and Its Silage with Cow Dung for Methane Production. Energies 2017, 10.

70. Martín, C.; Klinke, H. B.; Thomsen, A. B. Wet oxidation as a pretreatment method for enhancing the enzymatic convertibility of sugarcane bagasse. Enzyme. Microb. Technol. 2007, 40, 426.

71. Siqueira, G.; Arantes, V.; Saddler, J. N.; Ferraz, A.; Milagres, A. M. F. Limitation of cellulose accessibility and unproductive binding of cellulases by pretreated sugarcane bagasse lignin. Biotechnol. Biofuels. 2017, 10, 176. 
72. Neves, P. V.; Pitarelo, A. P.; Ramos, L. P. Production of cellulosic ethanol from sugarcane bagasse by steam explosion: Effect of extractives content, acid catalysis and different fermentation technologies. Bioresour. Technol. 2016, 208, 184.

73. Martins, L. H. d. S.; Rabelo, S. C.; Costa, A. C. d. Effects of the pretreatment method on high solids enzymatic hydrolysis and ethanol fermentation of the cellulosic fraction of sugarcane bagasse. Bioresour. Technol. 2015, 191, 312.

74. Yang, H.; Yan, R.; Chen, H.; Lee, D. H.; Zheng, C. Characteristics of hemicellulose, cellulose and lignin pyrolysis. Fuel 2007, 86, 1781.

75. Carrier, M.; Loppinet-Serani, A.; Denux, D.; Lasnier, J.; Ham-Pichavant, F.; Cansell, F.; Aymonier, C. Thermogravimetric analysis as a new method to determine the lignocellulosic composition of biomass. Biomass. Bioenergy. 2011, 35, 298.

76. Perrone, O. M.; Colombari, F. M.; Rossi, J. S.; Moretti, M. M. S.; Bordignon, S. E.; Nunes, C. d. C. C.; Gomes, E.; Boscolo, M.; Da-Silva, R. Ozonolysis combined with ultrasound as a pretreatment of sugarcane bagasse: Effect on the enzymatic saccharification and the physical and chemical characteristics of the substrate. Bioresource Technology 2016, 218, 69.

77. Karimi, K.; Taherzadeh, M. J. A critical review of analytical methods in pretreatment of lignocelluloses: Composition, imaging, and crystallinity. Bioresour. Technol. 2016, 200, 1008.

78. Zieliński, M.; Rusanowska, P.; Krzywik, A.; Dudek, M.; Nowicka, A.; Dębowski, M. Application of Hydrodynamic Cavitation for Improving Methane Fermentation of Sida hermaphrodita Silage. Energies 2019, 12, 525.

79. Wall, D. M.; O'Kiely, P.; Murphy, J. D. The potential for biomethane from grass and slurry to satisfy renewable energy targets. Bioresour. Technol. 2013, 149, 425.

80. Nizami, A.; Murphy, J. D. Optimizing the Operation of a Two-Phase Anaerobic Digestion System Digesting Grass Silage. Environ. Sci. Technol. 2011, 45, 7561.

81. Thamsiriroj, T.; Nizami, A. S.; Murphy, J. D. Why does mono-digestion of grass silage fail in long term operation? Appl. Energy. 2012, 95, 64.

82. Munir, S.; Daood, S. S.; Nimmo, W.; Cunliffe, A. M.; Gibbs, B. M. Thermal analysis and devolatilization kinetics of cotton stalk, sugar cane bagasse and shea meal under nitrogen and air atmospheres. Bioresour. Technol. 2009, 100, 1413.

83. Channiwala, S. A.; Parikh, P. P. A unified correlation for estimating HHV of solid, liquid and gaseous fuels. Fuel 2002, 81, 1051.

84. Jagadabhi, P. S.; Kaparaju, P.; Väisänen, A.; Rintala, J. Effect of macro- and micro-nutrients addition during anaerobic mono-digestion of grass silage in leach-bed reactors AU - Jagadabhi, Padma Shanthi. Environ. Technol. 2019, 40, 418.

85. Rodriguez, C.; Alaswad, A.; Benyounis, K. Y.; Olabi, A. G. Pretreatment techniques used in biogas production from grass. Renew. Sust. Energ. Rev. 2017, 68, 1193. 
86. Janke, L.; Leite, A.; Nikolausz, M.; Schmidt, T.; Liebetrau, J.; Nelles, M.; Stinner, W. Biogas Production from Sugarcane Waste: Assessment on Kinetic Challenges for Process Designing. Int. J. Mol. Sci. 2015, 16, 20685.

87. Badshah, M.; Lam, D. M.; Liu, J.; Mattiasson, B. Use of an Automatic Methane Potential Test System for evaluating the biomethane potential of sugarcane bagasse after different treatments. Bioresour. Technol. 2012, 114, 262.

88. Bolado-Rodríguez, S.; Toquero, C.; Martín-Juárez, J.; Travaini, R.; García-Encina, P. A. Effect of thermal, acid, alkaline and alkaline-peroxide pretreatments on the biochemical methane potential and kinetics of the anaerobic digestion of wheat straw and sugarcane bagasse. Bioresour. Technol. 2016, 201, 182.

\section{TOC/Graphic}

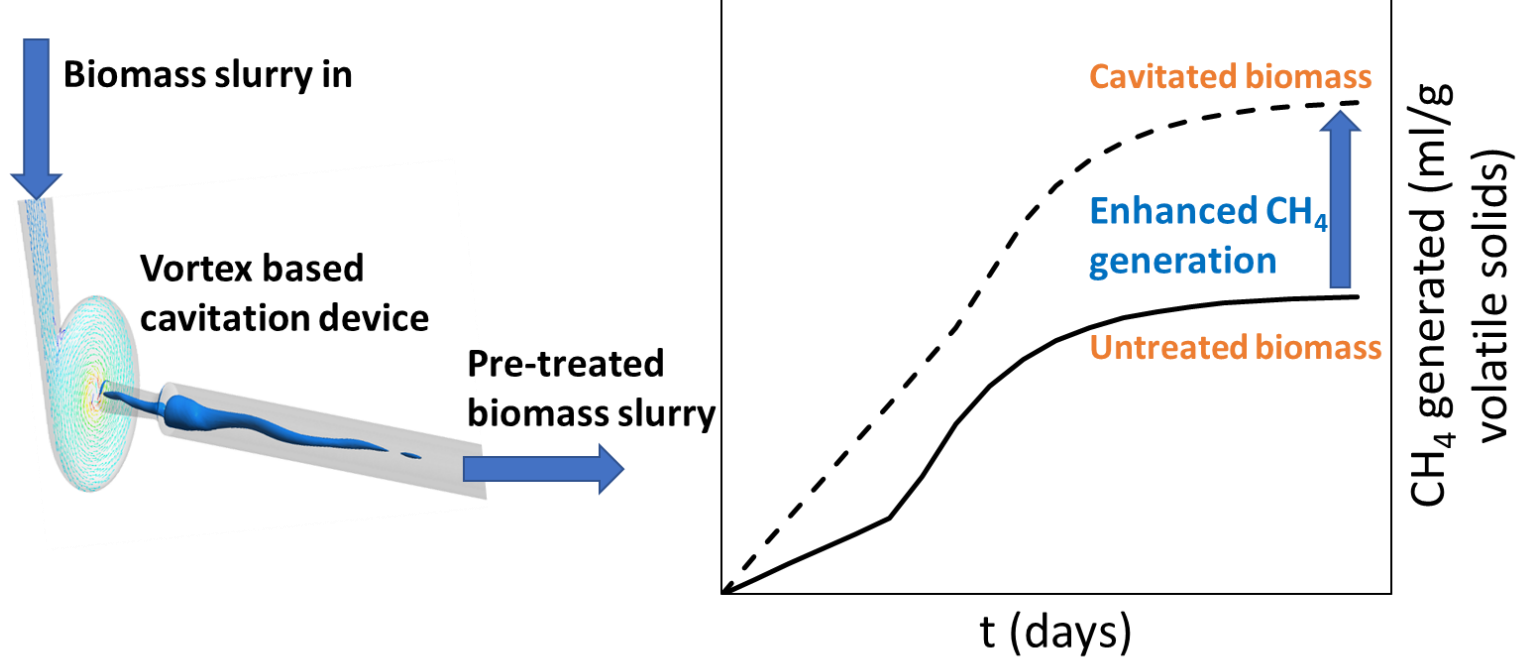

